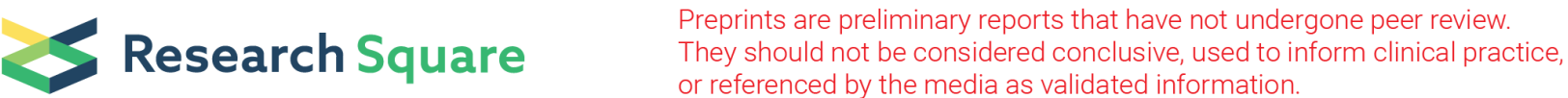

\section{Design and fabrication of ceramic hollow fiber membrane derived from waste ash using phase inversion-based extrusion/sintering technique for water filtration}

\section{Zhong Sheng Tai}

Universiti Teknologi Malaysia

Mohd Hafiz Dzarfan Othman ( $\nabla$ hafiz@petroleum.utm.my )

Universiti Teknologi Malaysia https://orcid.org/0000-0002-5842-2447

Mohd IIfan Hatim Mohamed Dzahir

Universiti Malaysia Perlis

Siti Khadijah Hubadillah

Universiti Teknologi Malaysia

Khong Nee Koo

Universiti Teknologi Malaysia

Mohd Ariff Azali

Universiti Teknologi Malaysia

Nur Hashimah Alias

Universiti Teknologi Malaysia

Azeman Mustafa

Universiti Teknologi Malaysia

Boon Seng Ooi

Universiti Sains Malaysia

Tonni Agustiono Kurniawan

Xiamen University

Ahmad Fauzi Ismail

Universiti Teknologi Malaysia

\section{Research Article}

Keywords: palm oil fuel ash, ceramic hollow fiber membrane, membrane morphology, phase inversion, sintering

Posted Date: August 24th, 2020 
DOI: https://doi.org/10.21203/rs.3.rs-62414/v1

License: (c) (1) This work is licensed under a Creative Commons Attribution 4.0 International License. Read Full License 


\section{Abstract}

Low-cost green ceramic hollow fiber membranes (CHFM) were successfully designed and fabricated from the industrial waste ash, palm oil fuel ash (POFA) via phase inversion-based extrusion/sintering techniques for water filter application. The extrusion process parameters such as suspension viscosity, air gap distance, and bore fluid flow rate were systematically explored to produce the membrane with the desired morphology. A high suspension viscosity would result in a small macro-voids structure. Moreover, a high air gap distance would induce fiber with long macro-voids structure, while a low bore fluid flow rate would lead to the formation of distorted lumen structure. The effect of sintering temperature towards CHFM was also studied in detail. An increase in sintering temperature improved the membrane bending strength, but also adversely affected the pure water flux due to lower porosity and higher tortuosity. The developed membranes achieved excellent bending strengths of $>75 \mathrm{MPa}$ at relatively low sintering temperatures than the alternative ceramic counterparts, due to its high potassium oxide, $\mathrm{K}_{2} \mathrm{O}$ content, which acted as the low melting point sintering aid. The relatively low sintering temperature of POFAderived CHFMs could reduce the energy consumption and sintering duration, which could be more economically attractive, as compared to their ceramic counterparts, thus benefiting industrial users.

\section{Introduction}

Porous ceramic hollow fiber membranes (CHFM) have gained so much interest in water treatment applications in recent years due to several remarkable advantages such as high durability at high operating temperature and pressure, exceptional mechanical strength, excellent resistance against corrosive agents/chemicals, high flux and separation efficiency, as well as easy to clean and regenerate. These advantages allow CHFM to attain long service time without frequent breakdown [1, 2]. Moreover, the hollow fiber membrane configuration consisting of shell and tube sides has high packing density with a large permeation area when it is assembled in a membrane module, offering high productivity at low energy consumption [3, 4]. Today, the majority of CHFM in the market are fabricated from high-purity alumina. In addition, alumina is known for its intrinsic refractory nature, hence, a very high sintering temperature (usually $\geq 1450^{\circ} \mathrm{C}$ ) is required to fabricate high-strength alumina membranes from micronsized alumina precursor powders [5-7]. The uses of costly alumina precursor powders and very high sintering temperatures result in high operational cost of ceramic membrane fabrication. In the last decade, an increasing number of studies have been devoted to the fabrication of CHFM using alternative materials such as natural materials (clays) [8-10] and sustainable solid wastes materials $[9,11,12]$. It is believed that the utilization of these low-cost alternative materials could reduce the membrane fabrication costs, making CHFM more cost-competitive.

Malaysia is naturally endowed with tropical biodiversity such as palm oil. The palm oil industry is considered as one of the world's largest agriculture industries. The global palm oil production volume was over 77 million tons in 2018 [13]. According to the European Palm Oil Alliance [14], palm oil and palm kernel oil account for over one-third of the global vegetable oil production. The rapid development of the palm oil industry leads to the generation of colossal amounts of by-products that could pose threats to 
the surrounding environment and local communities. Palm oil fuel ash (POFA) is among the major byproducts from the burning of palm kernel shells, palm oil fiber, and palm oil husk. POFA contains a large amount of crystalline silica in the form of quartz [12]. To add its technological values, POFA could be harnessed for the fabrication of low-cost silica-based CHFM for water treatment. Typically, the fabrication of silica-based ceramic membranes involves comparatively low sintering temperature than that of alumina-based membranes $[9,11,15]$. The crystalline silica phase also gives the membranes with better mechanical strength than the amorphous phase [9]. Besides, POFA also has high porosity that is attributed to its composition consisting of various inorganic oxides $[12,16]$. The abundant silanol group on the rudimentary porous structure of POFA makes it prone to adsorption, separation, and catalysis processes [17].

Apart from the selection of raw materials, the fabrication cost of CHFM can also be reduced using simplified and efficient fabrication techniques. In general, ceramic membranes for water treatment applications exhibit multilayer asymmetric microstructure, in which the denser layers contribute to the separation mechanisms, whereas the less dense porous layers provide the mechanical support to the membranes. The fabrication of asymmetric structured CHFM typically involves multiple steps that are time and energy-consuming. Recently, the combined phase inversion and sintering methods have attracted popularity for the fabrication of $\operatorname{CHFM}[7,18,19]$. This method enables asymmetric structured CHFM to be produced in a single step with one heat treatment session only $[3,20]$.

Usually, the CHFM prepared via this method has two distinct structures, namely sponge- and finger-like structures. The dense sponge-like layer with the smallest packing pore size acts as the separation layer and contributes to the mechanical strength of the membranes. The finger-like structure reduces the mass transfer resistance, but also detriments the membrane strength $[18,20]$. High mechanical strength is particularly crucial for CHFM to ensure the long-term performance stability of the membranes [21, 22]. Past studies have witnessed the manipulation of the phase inversion parameters and sintering temperatures to augment the mechanical strength of CHFM $[5,9]$. The variation of these parameters would change the morphological structure of the membrane, and as a result, affecting the mechanical strength of the membranes.

Recently, our group has investigated the feasibility of the green POFA-derived CHFM for oily water separation and heavy metal adsorption $[12,23,24]$. These membranes successfully demonstrated outstanding filtration and adsorption performances. However, a detailed study on the effects of the phase inversion-based extrusion/sintering method conditions towards acquiring POFA-derived CHFM with high strength has not yet been explored. Hence, a thorough investigation of the effects of phase inversion parameters such as suspension viscosity, air gap distance and bore fluid flow rate on the morphological and mechanical properties of membranes was conducted. The effects of sintering temperature on the membrane properties such as microstructure, surface properties, mechanical properties, pore size, porosity, and water permeation performance were also thoroughly examined. This study would expand the understanding of the development of CHFM from the green alternative materials, especially the waste 
materials with relatively large particle sizes. In the last part of this study, the properties of the POFAderived CHFM were compared with other alternative CHFMs reported in the literature.

\section{Materials And Procedures \\ 2.1 Materials}

The raw POFA was supplied by a crude palm oil mill in Chaah, Johor, Malaysia. The raw ash was first ground into smaller particles using a Waring Model $800 \mathrm{G}$ blender, followed by the thermal pre-treatment in a Nabertherm Model LT $5 / 12$ muffle furnace at $700^{\circ} \mathrm{C}$ for 2 hours with a heating rate of $5^{\circ} \mathrm{C} / \mathrm{min}$. The pre-treated POFA was further ground by ball-milling at $200 \mathrm{rpm}$ for a week and sieved to the particle sizes of $<36 \mu \mathrm{m}$ before the membrane fabrication. Table 1 shows the chemical compositions of POFA as determined by X-ray fluorescence (XRF) analysis. N-methyl-2-pyrrolidone (NMP, EMPLURA®, Merck), polyethersulfone (PES, Radel A-300, Ameco Performance), and Arlacel P135 (Polyethylene glycol 30dipolyhydroxystearate, CRODA) were used as the solvent, binder, and dispersant, respectively for the preparation of the ceramic suspensions. Furthermore, tap water was used as the internal and external coagulants during the phase inversion extrusion process.

Table 1

Chemical compositions of POFA as determined by XRF analysis

\begin{tabular}{|ll|}
\hline Metal oxide & Composition (wt\%) \\
\hline $\mathrm{SiO}_{2}$ & 74.5 \\
\hline $\mathrm{K}_{2} \mathrm{O}$ & 6.4 \\
\hline $\mathrm{Al}_{2} \mathrm{O}_{3}$ & 5.2 \\
\hline $\mathrm{CaO}$ & 3.3 \\
\hline $\mathrm{MgO}$ & 3.4 \\
\hline $\mathrm{Fe}_{2} \mathrm{O}_{3}$ & 3.1 \\
\hline $\mathrm{P}_{2} \mathrm{O}_{5}$ & 2.5 \\
\hline $\mathrm{SO}_{3}$ & 1.0 \\
\hline $\mathrm{TiO}_{2}$ & 0.2 \\
\hline $\mathrm{Mn}_{2} \mathrm{O}_{3}$ & 0.1 \\
\hline
\end{tabular}

\subsection{Preparation of POFA-derived ceramic hollow fiber membrane}


The POFA-derived CHFMs were developed via phase inversion-based extrusion/sintering method. Ceramic suspensions with different POFA loadings ranging from $40 \mathrm{wt} \%-60 \mathrm{wt} \%$ were prepared. In the suspension preparation, $1 \mathrm{wt} \%$ of Arlacel P135 was first mixed with NMP, followed by the addition of POFA with gentle stirring. The suspension was then subjected to ball-milling in a NQM-2 planetary ball mill system at $190 \mathrm{rpm}$ for 48 hours before the addition of PES. $5 \mathrm{wt} \%$ of PES was added to the suspension which was then further ball-milled to acquire a uniform suspension. After 48 hours, the suspension was degassed under vacuum with gentle stirring for 30 minutes to remove the entrained air bubbles that might cause membrane defects. After degassing, the ceramic suspension was immediately transferred to a $100 \mathrm{~mL}$ stainless steel syringe and extruded through a tube-in-orifice spinneret (outer diameter: $2.8 \mathrm{~mm}$; inner diameter: $0.5 \mathrm{~mm}$ ) at an extrusion rate of $10 \mathrm{~mL} / \mathrm{min}$ into a tap water coagulant bath. The schematic diagram of the tube-in-orifice for single-layer hollow fiber precursors is shown in Figure A.1 in the Appendices. The air gap distance between the spinneret and water bath was varied from 5 to $15 \mathrm{~cm}$. Moreover, tap water was used as the internal coagulant (bore fluid) with flow rates ranging from 6 to $20 \mathrm{~mL} / \mathrm{min}$. The hollow fiber precursors obtained from the extrusion process were soaked in tap water for 24 hours to complete the phase inversion process, followed by the overnight drying at room temperature. Finally, the precursors were sintered at the temperature ranging from $1025^{\circ} \mathrm{C}-1100^{\circ} \mathrm{C}$ in an air atmosphere using a XY-1700 Magna tubular furnace. The sintering profile of the POFA-derived CHFM is depicted in Figure A.2 in the Appendices. The membrane fabrication parameters are summarized in Table 2. 
Table 2

Fabrication parameters of POFA-derived CHFM

\begin{tabular}{|c|c|c|c|c|c|}
\hline Sample & $\begin{array}{l}\text { POFA } \\
\text { loading } \\
\text { (wt\%) }\end{array}$ & $\begin{array}{l}\text { Suspension flow } \\
\text { rate }(\mathrm{mL} / \mathrm{min})\end{array}$ & $\begin{array}{l}\text { Bore fluid flow } \\
\text { rate (mL/min) }\end{array}$ & $\begin{array}{l}\text { Air gap } \\
\text { distance } \\
\text { (cm) }\end{array}$ & $\begin{array}{l}\text { Sintering } \\
\text { temperature } \\
\text { ('C) }\end{array}$ \\
\hline C-P40 & 40 & 10 & 9 & 5 & 1050 \\
\hline C-P45 & 45 & 10 & 9 & 5 & 1050 \\
\hline C-P50 & 50 & 10 & 9 & 5 & 1050 \\
\hline C-P55 & 55 & 10 & 9 & 5 & 1050 \\
\hline C-A5 & 55 & 10 & 9 & 5 & 1050 \\
\hline C-A7 & 55 & 10 & 9 & 7 & 1050 \\
\hline C-A10 & 55 & 10 & 9 & 10 & 1050 \\
\hline C-A15 & 55 & 10 & 9 & 15 & 1050 \\
\hline C-B6 & 55 & 10 & 6 & 5 & 1050 \\
\hline C-B9 & 55 & 10 & 9 & 5 & 1050 \\
\hline C-B12 & 55 & 10 & 12 & 5 & 1050 \\
\hline C-B15 & 55 & 10 & 15 & 5 & 1050 \\
\hline C-B20 & 55 & 10 & 20 & 5 & 1050 \\
\hline C-S1 & 55 & 10 & 9 & 5 & 1025 \\
\hline C-S2 & 55 & 10 & 9 & 5 & 1050 \\
\hline C-S3 & 55 & 10 & 9 & 5 & 1075 \\
\hline C-S4 & 55 & 10 & 9 & 5 & 1100 \\
\hline
\end{tabular}

\subsection{Characterization of POFA-derived ceramic hollow fiber membrane}

The chemical composition of the POFA was determined via XRF analysis using a X-Supreme 8000 Oxford Equipment. The viscosity of the ceramic suspension was analyzed via a Brookfield viscometer at the shear rates ranging from $0.3 \mathrm{~s}^{-1}$ to $100 \mathrm{~s}^{-1}$ at room temperature. The cross-sectional and surface morphologies of the as-prepared CHFM were observed through scanning electron microscopy (SEM) analysis (Hitachi TM3000) at various magnifications. The membrane samples were coated with platinum under vacuum for several minutes before the SEM analysis. The radial shrinkage of the CHFM was also determined from the SEM images. The flexural strength of the CHFM was determined via a three-point bending test using an Instron 3342 tensile tester. Each measurement was repeated three times $(n=3)$ to ensure the accuracy of the results. The bending strength, $\sigma_{F}(\mathrm{MPa})$ was then calculated using Eq. (1). 
$\sigma_{F}=8 F L D_{o} / \pi\left(D_{o}^{4}-D_{i}^{4}\right)$

where $F$ is the force at which the hollow fiber membrane fractured $(N), L$ is the length of the membrane $(\mathrm{m})$, whereas $D_{o}$ and $D_{i}$ are the outer and inner diameters of the membranes $(\mathrm{m})$, respectively. The surface roughness of the CHFM prepared at different sintering temperatures was investigated via atomic force microscopy (AFM) analysis using XE-100 AFM from Park Systems by tip-scanning with a scan size of $10 \mu \mathrm{m} \times 10 \mu \mathrm{m}$. A Micromeritics Autopore IV 9510 mercury porosimeter was used to characterize the pore size distribution (PSD), porosity, and tortuosity factor of the membranes sintered at different temperatures $\left(1025^{\circ} \mathrm{C}-1100^{\circ} \mathrm{C}\right)$. The pure water flux (PWF) performance of the membranes was tested using a homemade crossflow filtration system. The flux performance test was conducted at a pressure of 2 bar at room temperature for one hour. The test was repeated three times $(n=3)$ for each sample. Before starting the experiment, the membranes were stabilized by running the pure water through the membranes at constant pressure for 10 minutes. PWF $\left(L / m^{2} h\right)$ was calculated using the following equation.

$\mathrm{PWF}=V / \operatorname{At}(2)$

where $V$ is the cumulative volume of permeate water collected $(L), A$ is the total permeation area of the membrane $\left(\mathrm{m}^{2}\right)$ and $t$ is the time taken to collect $V$ (1 hour).

\section{Results And Discussion}

\subsection{Morphology controls and bending properties of hollow fiber membranes}

\subsubsection{Effect of POFA loading}

The POFA loading of the ceramic suspension was varied to investigate the effect of suspension viscosity on the CHFM morphology. Figure 1 illustrates the rheological behaviors of suspensions with different POFA loadings. All the suspensions demonstrated the shear-thinning behaviors in which the suspension viscosity decreased with increasing shear rate from $5 \mathrm{~s}^{-1}$ to $100 \mathrm{~s}^{-1}$ (Fig. 1A). These rheological behaviors were typical non-Newtonian flows that are commonly found in many ceramic slurries [25-27]. Figure 1B shows the suspension viscosity at the shear rate of $25 \mathrm{~s}^{-1}$. It could be seen that the suspension viscosity increased slowly with the increase in POFA loading for the suspensions with low POFA loading ( $<55 \mathrm{wt} \%$ ). However, the suspension viscosity increased drastically with a further increase in POFA loading when the POFA loading exceeded the critical value (55 wt\%). When the POFA loading was beyond the critical value, there was limited free liquid (solvent) and the particles could easily mingle with each other in the suspension creating frictional interactions, which resulted in a sharp increase in suspension viscosity [28]. A similar trend was also observed by Liu et al. [29] who reported that a sharp increase in 
nickel oxide/yttria-stabilized zirconia ceramic suspension viscosity occurred with further increase in solid loading when the solid loading exceeded the critical value of $75.6 \mathrm{wt} \%$.

Past studies have witnessed that suspension viscosity is the dominating factor that affects the morphology of the CHFM prepared via phase inversion technique [18, 29, 30]. Often, suspension viscosity can also affect the spinnability of the suspension [31]. In this part of the study, CHFMs were prepared with different POFA loadings ranging from $40 \mathrm{wt} \%$ to $55 \mathrm{wt} \%$. These membranes are denoted as C-P40, CP45, C-P50, and C-P55 based on the POFA loading used. Meanwhile, the suspension with 60 wt\% POFA loading was too viscous to extrude through the spinneret during the hollow fiber forming process.

Figure 2 shows the SEM images of the cross-sections and surface morphologies of the CHFM prepared with different POFA loadings that sintered at $1050^{\circ} \mathrm{C}$. C-P40 derived from the lowest solid loading exhibited a sandwich structure, which was a thin central sponge-like layer between two finger-like structures, as shown in Fig. 2A2. The thicknesses of the finger-like near the inner and outer regions were approximately $52 \%$ and $42 \%$ of the overall wall thickness, respectively. When the POFA loading was increased to $45 \mathrm{wt} \%$, the finger-like structure near the outer region disappeared, while the finger-like macro-voids layer near the inner region extended to $53 \%$ of the overall wall thickness. However, the thickness of the finger-like macro-voids layer decreased to $51 \%$ and $39 \%$ of the overall wall thickness when the POFA loading was increased to $50 \mathrm{wt} \%$ and $55 \mathrm{wt} \%$, respectively. Additionally, the width of the finger-like voids also decreased with increasing POFA loading.

The morphological difference in CHFM derived from different POFA loading can be explained with a viscous fingering mechanism. As the fiber left the spinneret to travel in the $5 \mathrm{~cm}$ air gap, the exposure of the fiber to the atmosphere resulted in the simultaneous solvent evaporation and non-solvent (moisture in the atmosphere) condensation, causing a rapid increase in the local viscosity at the outer surface of the fiber before immersion in the coagulant bath $[18,32]$. The increase in the viscosity of the outer fiber surface inhibited the viscous fingering phenomenon and the subsequent growth of the finger-like voids at the outer region of the fiber. Based on Fig. 1, the suspension viscosity was higher with increasing POFA loading, which consequently suppressed the viscous fingering phenomenon. As a result, the finger-like structure was not seen in the outer region for the CHFM derived with the POFA of $45 \mathrm{wt} \%$ and above.

The thickness of the finger-like structure near the inner region of C-P45 increased to $53 \%$ of the overall wall thickness as the invading micro-streams from the inner surface experienced less momentum loss when the finger-like formation at the outer surface was prevented. According to García-Fernández et al. [5], the invading non-solvent micro-streams would lose momentum when two sets of micro-streams met from the opposite directions, resulting in thinner finger-like structures originating from both surfaces with a sponge-like layer sandwiched in between them. Meanwhile, the thickness of the finger-like structure near the inner region decreased when the POFA loading was further increased from $45 \mathrm{wt} \%$ to $55 \mathrm{wt} \%$, which was due to higher suspension viscosity that posed greater resistance and friction against the invading non-solvent micro-streams. Simultaneously, the increase in the POFA loading also led to a lower polymer/POFA particle ratio which reduced the polymer coverage of the POFA particle in the suspension. 
Consequently, the POFA particle might aggregate and hinder the consolidation of the finger-like microchannels into larger finger-like macro-voids [29]. Therefore, the width of the finger-like voids decreased with increasing POFA loading.

Interestingly, the sponge-like layer of the POFA-derived CHFM was relatively less dense as compared to other CHFM derived from pure metal oxides $[5,29,31]$. Such a loosely packed sponge-like structure is commonly found in the CHFM derived from waste ash due to large particle sizes [11, 33]. Generally, the waste ash can exhibit the particle sizes of larger than $10 \mu \mathrm{m}$, whereas the sizes of pure metal oxide particles are much finer (usually about $1 \mu \mathrm{m}$ ) $[5,18,34,35]$. The particle size distribution curve in Fig. 3 shows that the majority of the POFA particles exhibited the sizes ranging from $2.8 \mu \mathrm{m}$ to $25.8 \mu \mathrm{m}$ with a mean size of $8.0 \mu \mathrm{m}$. The large particle size of POFA resulted in a less dense sponge-like structure due to longer interparticle distance. Moreover, the notable content of residual organic matters such as carbon could also be a reason that led to the less dense sponge-like structure in the POFA-derived CHFM. During sintering, some voids were created in the membrane structure due to the oxidation of the organic matters which resulted in larger membrane pore size [12].

Table 3 shows the bending strength of the CHFM derived from different POFA loadings. The bending strength of the membranes increased from 59.7 MPa to 98.1 MPa when the POFA loading was increased from $40 \mathrm{wt} \%$ to $55 \mathrm{wt} \%$. C-P40 exhibited the lowest bending strength due to the extensive finger-like structures near the inner and outer regions of the membranes with only a thin sponge-like layer sandwiched in between them. The sponge-like layer was thicker for the CHFM derived from higher POFA loading which bestowed them with enhanced mechanical strength. In addition, the increase in the mass of POFA particles at higher loading also contributed to ameliorating the bending strength properties of $\mathrm{CHFM}$. This can be explained by the mass transport mechanism during the sintering process [19]. As commonly known, the sintering of ceramic particles commenced at the contact areas of the particles [36, 37]. At higher POFA loading, the particles were more densely arranged and had more contact points with neighboring particles which prompted more extensive neck growth between the particles. This created bonds between the particles that consolidated the strength of the POFA particles, thereby enhancing the mechanical properties of CHFM.

Table 3

Bending strength of the CHFMs derived from different POFA loading $(\mathrm{n}=3)$

\begin{tabular}{|ll|}
\hline Membrane & Bending strength (MPa) \\
\hline C-P40 & $59.7 \pm 3.3$ \\
\hline C-P45 & $75.5 \pm 1.7$ \\
C-P50 & $83.9 \pm 2.2$ \\
C-P55 & $98.1 \pm 1.8$ \\
\hline
\end{tabular}

\subsubsection{Effect of air gap distance}


In this part of the study, POFA-derived CHFMs were fabricated using 55 wt\% POFA loading due to the highest bending strength achieved in the previous section. High mechanical strength is essential for CHFM to ensure that the membranes can be assembled and packed into the modules without breaking [2]. The literature has revealed that the extremely low air gap distance, such as $0 \mathrm{~cm}$, leads to the formation of a sandwich structure with a thin central sponge-like layer in between finger-like structures originating from both inner and outer surfaces $[18,29]$. As discussed in the section earlier, the local viscosity at the outer surface of the fiber increases when traveling through the air gap before contacting the coagulant bath. When no air gap is applied, the fiber falls directly into the coagulant bath without experiencing an increase in local viscosity at the outer surface of the fiber, which favors the growth of a finger-like structure near the outer region of the fiber. The extensive finger-like structure at both inner and outer regions of the membrane is detrimental to the mechanical strength of CHFM. Hence, in this section, the fibers were spun with air gap distances of $5 \mathrm{~cm}, 7 \mathrm{~cm}, 10 \mathrm{~cm}$, and $15 \mathrm{~cm}$, followed by sintering at 1 $050^{\circ} \mathrm{C}$; they are represented as C-A5, C-A7, C-A 10 , and C-A 15 , respectively depending on the air gap distance applied. It is noted that C-A5 is the same as C-P55 in the previous section.

Based on Fig. 4A2 to D2, the thickness of the finger-like macro-voids structure increased with increasing air gap distance. The thickness of the finger-like macro-voids structure slightly increased from $39-41 \%$ when the air gap distance was increased from $5 \mathrm{~cm}$ to $7 \mathrm{~cm}$. C-A15 exhibited the thickest finger-like macro-voids structure with it sprawling across $71 \%$ of the overall wall thickness. Moreover, the width of the finger-like macro-voids also increased with the increase in air gap distance. As displayed in Fig. 4A1 to D1, the outer diameter and wall thickness decreased with increasing air gap distance. The diameter of CHFM decreased from $1.46 \pm 0.02 \mathrm{~mm}$ to $1.25 \pm 0.06 \mathrm{~mm}$ when the air gap distance was increased from $5 \mathrm{~cm}$ to $10 \mathrm{~cm}$. C-A15 which was fabricated with the longest air gap distance demonstrated the smallest external diameter of $1.16 \pm 0.04 \mathrm{~mm}$. Furthermore, the membrane wall thickness also decreased from $210 \mu \mathrm{m}$ to $149 \mu \mathrm{m}$ when the air gap distance was increased from $5 \mathrm{~cm}$ to $15 \mathrm{~cm}$.

The variation in the length of the finger-like macro-voids structure originating from the inner surface was caused by the difference in the contact period between the bore fluid and hollow fibers. Longer air gap distance provided more time for the invading micro-streams to penetrate further into the fiber, resulting in a thicker finger-like structure $[7,18]$. The fiber also experienced the circumferential stress exerted by the bore fluid for longer duration at higher air gap distance, thereby causing the width of the finger-like macrovoids to increase [19]. The long exposure to the circumferential stress by the bore fluid also reduced the membrane wall thickness. Concurrently, at higher air gap distance, the fiber also faced greater longitudinal stress by gravity due to long distance between the spinneret and coagulant bath, which resulted in the reduction in wall thickness and external diameter of the membrane, as indicated in Fig. 4Al to $\mathrm{D} 1[38,39]$.

Table 4 summarizes the bending strength of the POFA-derived CHFM spun at various air gap distances. The bending strength of the membranes decreased with increasing air gap distance. C-A5 had the strongest bending strength with a value of $98.1 \mathrm{MPa}$. The bending strength dropped to $88.5 \mathrm{MPa}$ when the air gap distance was increased to $7 \mathrm{~cm}$. A significant decrease in bending strength to $66.6 \mathrm{MPa}$ was

Page $11 / 31$ 
observed when the air gap distance was further increased to $10 \mathrm{~cm}$. The bending strength then slightly reduced to $64.5 \mathrm{MPa}$ for the CHFM spun at a $15 \mathrm{~cm}$ air gap distance. The decrease in bending strength of CHFM with increasing air gap distance was most likely attributed to the formations of thicker finger-like macro-voids structure and thinner membrane wall.

Table 4

Bending strength of the CHFMs spun at different air gap distance $(n=3)$

\begin{tabular}{|ll|}
\hline Membrane & Bending strength (MPa) \\
\hline C-A5 & $98.1 \pm 1.8$ \\
\hline C-A7 & $88.5 \pm 1.6$ \\
\hline C-A10 & $66.6 \pm 0.5$ \\
\hline C-A15 & $64.5 \pm 1.4$ \\
\hline
\end{tabular}

\subsubsection{Effect of bore fluid flow rate}

To study the effect of bore fluid flow rate, POFA-derived CHFM precursors were prepared using the suspensions with $55 \mathrm{wt} \%$ POFA loading and spun at the air gap distance of $5 \mathrm{~cm}$ with different bore flow rates of $6 \mathrm{~mL} / \mathrm{min}, 9 \mathrm{~mL} / \mathrm{min}, 12 \mathrm{~mL} / \mathrm{min}, 15 \mathrm{~mL} / \mathrm{min}$ and $20 \mathrm{~mL} / \mathrm{min}$. The precursors were then sintered at $1050^{\circ} \mathrm{C}$ to acquire CHFM. These membranes are denoted as C-B6, C-B9, C-B12, C-B15, and C-B20 based on the bore fluid flow rates applied for spinning. Again, it is noted that C-B9 is the same as C-A5 in the previous section, which demonstrated the strongest bending strength.

Based on Fig. 5A1, the deformation of the lumen could be observed when the bore fluid flow rate of $6 \mathrm{~mL} / \mathrm{min}$ was used. During phase inversion, the rate of solvent diffusing out of the ceramic suspension is faster than that of coagulant (water) diffusing into the ceramic suspension, which results in the shrinkage of hollow fiber [40]. The shrinkage of the hollow fiber creates a large inward radial force towards the lumen side. At the same time, the ballooning effect of the bore fluid in the lumen helps to retain the uniform shape of the lumen. In this study, the lumen deformed when a low bore fluid flow rate $(6 \mathrm{~mL} / \mathrm{min}$ ) was applied due to insufficient hydrodynamic force generated by the bore fluid against the relatively large inward radial force [7]. In addition, the de-mixing process was also afflicted by the low bore fluid flow rate which led to the partial solidification of polymer near the inner surface of the fiber. The partially solidified polymer was not strong enough to withstand the inward radial force, thereby resulting in the deformation of the lumen [7]. With increasing bore fluid flow rate to $9 \mathrm{~mL} / \mathrm{min}$, a more rigid lumen surface was formed due to the rapid de-mixing process and complete solidification of polymer near the inner surface of the fiber. As a result, the uniform round-shaped lumen was obtained as illustrated in Fig. 5B1.

The lumen diameter of CHFM increased gradually from $980 \mu \mathrm{m}$ to $999 \mu \mathrm{m}$ when the bore fluid flow rate was increased from $9 \mathrm{~mL} / \mathrm{min}$ to $15 \mathrm{~mL} / \mathrm{min}$ (Fig. 5B1 and D1). Furthermore, C-B20 exhibited the largest lumen diameter of $1.53 \mathrm{~mm}$ (Fig. 5E1). Meanwhile, there was no obvious increase in the external diameter 
of CHFM when the bore fluid flow rate was increased from $9 \mathrm{~mL} / \mathrm{min}$ to $15 \mathrm{~mL} / \mathrm{min}$, but it increased substantially at the bore fluid flow rate of $20 \mathrm{~mL} / \mathrm{min}$. Besides, the membrane wall thickness also decreased from $210 \mu \mathrm{m}$ to $175 \mu \mathrm{m}$ with the increase of bore fluid flow rate from $9 \mathrm{~mL} / \mathrm{min}$ to $20 \mathrm{~mL} / \mathrm{min}$. This could be explained by the large hydrodynamic force exerted by the bore fluid that pushed the ceramic suspension outward radially. As a result, the membrane acquired a larger lumen diameter with a thinner membrane wall when a higher bore fluid flow rate was applied. For C-B20, the bore fluid flow rate was too high that the bore fluid pushed the ceramic suspension outward rapidly, which resulted in the formation of the extremely large lumen and external diameter with a thin membrane wall.

As shown in the higher magnification (400x) SEM images, the thickness of the finger-like macro-voids structure near the inner surface increased with increasing bore fluid flow rates (Fig. 5A2 to E2). The fingerlike macro-voids structure increased in thickness and occupied $59 \%$ of the overall wall thickness when the bore fluid flow rate was increased from $9 \mathrm{~mL} / \mathrm{min}$ to $15 \mathrm{~mL} / \mathrm{min}$. The membrane prepared with the bore fluid flow rate of $20 \mathrm{~mL} / \mathrm{min}$ possessed the largest finger-like macro-voids structure of approximately $60 \%$ of the overall membrane wall thickness. At high bore fluid flow rate, the fast-moving bore fluid helped to remove the exchanged solvent accumulated near the coagulant-ceramic suspension interface at the lumen side. The removal of the accumulated exchanged solvent could maintain the initial concentration gradient of the solvent across the coagulant-ceramic suspension interface, which enhanced the solvent and non-solvent exchange rate, thereby resulting in thicker finger-like macro-voids structure [5].

As expected, the bending strength of the CHFM decreased with increasing bore fluid flow rates as shown in Table 5. The bending strength of the membranes decreased from 98.1 MPa to $61.9 \mathrm{MPa}$ when the bore fluid flow rate was increased from $9 \mathrm{~mL} / \mathrm{min}$ to $20 \mathrm{~mL} / \mathrm{min}$. Similarly, the reduction in the bending strength of the membranes was mainly due to the increase in finger-like structure thickness and thinner membrane wall. Interestingly, despite having a thicker membrane wall, C-B6 exhibited a bending strength of $81.8 \mathrm{MPa}$, which was lower than that of C-B9. This could be due to the deformed lumen structure that afflicted the membrane mechanical properties.

Table 5

Bending strength of the CHFMs prepared at different bore fluid flow rates $(n=3)$

\begin{tabular}{|ll|}
\hline Membrane & Bending strength (MPa) \\
\hline C-B6 & $81.8 \pm 0.7$ \\
C-B9 & $98.1 \pm 1.8$ \\
C-B12 & $75.6 \pm 1.2$ \\
C-B15 & $69.1 \pm 1.3$ \\
C-B20 & $61.9 \pm 1.1$ \\
\hline
\end{tabular}

\subsection{Effect of sintering temperature on membrane properties}




\subsubsection{Microstructure and surface properties}

The hollow fiber precursors were prepared using the suspensions with 55 wt\% POFA loading and spun at $5 \mathrm{~cm}$ air gap distance and $9 \mathrm{~mL} / \mathrm{min}$ bore fluid flow rate. As indicated in Table 1, POFA contained a substantial amount of $\mathrm{K}_{2} \mathrm{O}(6.4 \mathrm{wt} \%)$. The melting point of $\mathrm{K}_{2} \mathrm{O}$ is $740^{\circ} \mathrm{C}$, which is much lower than the sintering temperature of POFA, hence, it could act as an intrinsic liquid phase sintering aid to improve the sintering behaviors of POFA. Hence, a small range of sintering temperatures of $1025^{\circ} \mathrm{C}$ to $1100^{\circ} \mathrm{C}$ was selected for this part of the study. The membranes were sintered at $1025^{\circ} \mathrm{C}, 1050^{\circ} \mathrm{C}, 1075^{\circ} \mathrm{C}$, and 1 $100^{\circ} \mathrm{C}$, which are labeled as C-S1, C-S2, C-S3, and C-S4, respectively.

Figure 6 displays the cross-section and outer surface morphologies of the CHFM sintered at different temperatures. As mentioned earlier, the POFA used in this study demonstrated a broad particle size distribution ranging from $2.80 \mu \mathrm{m}$ to $25.8 \mu \mathrm{m}$. At a low sintering temperature of $1025^{\circ} \mathrm{C}$, neck formation only occurred between small grains, whereas the large grains did not experience any observable neck growth (Fig. 5.6A1). As the sintering temperature was increased to $1050^{\circ} \mathrm{C}$, significant grain growth occurred between the large grains (Fig. 5.6B1 and B2). At this temperature, the grains grew and consumed the adjacent grains to form larger grains, which resulted in a decrease in grain number. A network of interconnected grains was formed when the sintering temperature was increased to $1075^{\circ} \mathrm{C}$ (Fig. 5.6C1). The neck growth and grain diffusion were more vigorous for the membrane sintered at 1 $100^{\circ} \mathrm{C}$ as could be seen from the interconnected grain structure with larger grain size and thicker neck at the membrane cross-section (Fig. 5.6D1).

The rapid change in the microstructure of POFA-derived CHFM at a small sintering temperatures range of $1025^{\circ} \mathrm{C}$ to $1100^{\circ} \mathrm{C}$ was attributed to the presence of $\mathrm{K}_{2} \mathrm{O}$ which acted as an intrinsic liquid phase sintering aid. In our previous work, the SEM images demonstrated that the surface of the POFA particles started to become smooth and the particle grew larger when the pre-treatment temperature was increased to $700^{\circ} \mathrm{C}$ [12]. The findings suggested that $\mathrm{K}_{2} \mathrm{O}$ had melted at the temperature of $700^{\circ} \mathrm{C}$ and facilitated the diffusion between particles. During the membrane sintering process at elevated temperatures, the POFA grains were enveloped by the liquid phase $\mathrm{K}_{2} \mathrm{O}$. The $\mathrm{K}_{2} \mathrm{O}$ liquid could adhere to the adjacent grains via capillarity which increased the contact area between the grains, thereby facilitating mass transport and densification $[41,42]$.

The liquid phase aided membrane mass transport process can be explained by three mechanisms, namely contact flattening, dissolution of small grains, and solid-state bonding [43]. In the contact flattening mechanism, the grains were pulled together due to the capillary pressure and surface tension of the $\mathrm{K}_{2} \mathrm{O}$ liquid. Due to the capillary stress at the contact area between the grains, the solid dissolved in the liquid and was transported to the surface of the neck $[43,44]$. The contact flattening tended to occur at small grains due to large contact stresses, which also explained the neck growth at the small grains at the sintering temperature of $1025^{\circ} \mathrm{C}$. At the temperature of $1050^{\circ} \mathrm{C}$, the mass transport in the way that the small grains dissolved in the liquid $\mathrm{K}_{2} \mathrm{O}$ and reprecipitated on the large grains. As a result, large grains 
grew larger while the small grains were eliminated, as depicted in Fig. 6B1. The solid-state bonding mechanism might occur when the sintering temperature was further increased to $1075^{\circ} \mathrm{C}$ and $1100^{\circ} \mathrm{C}$. This mechanism involved the grain growth by diffusion along the liquid wetted grain boundary [45, 46]. At this stage, the membrane structure experienced densification and shrinkage.

From the SEM image in Fig. 6A2, it could be seen that the outer surface of the membrane was rough after sintering at $1050^{\circ} \mathrm{C}$. This result was further confirmed by the AFM image that showed a mass of small peaks (brighter region) and valleys (darker region) with a mean surface roughness $\left(R_{a}\right)$ of $0.340 \mu \mathrm{m}$

(Fig. 7A). It is noted that the black spots in the AFM images indicate the membrane pores. The number of black spots (pores) on the membrane surface decreased for the membranes sintered at higher temperatures, signifying lower surface porosity which was consistent with the SEM images of the outer membrane surface (Fig. 6A2 to D2). The $R_{a}$ value increased considerably to $0.379 \mu \mathrm{m}$ when the sintering temperature was increased to $1050^{\circ} \mathrm{C}$. According to Talebi et al. [47], the mean surface roughness of the film would increase when the grain growth had started. In their study, the $R_{a}$ values of the yttria-stabilized zirconia electrolyte film decreased from 45.3 to $26.7 \mathrm{~nm}$ when the sintering temperature was increased from $1300^{\circ} \mathrm{C}$ to $1400^{\circ} \mathrm{C}$. However, due to the grain growth phenomenon, the $R_{a}$ value bounced to $48.7 \mathrm{~nm}$ for the film sintered at $1500^{\circ} \mathrm{C}$. In this study, significant grain growth between particles of different sizes started to occur at $1050^{\circ} \mathrm{C}$, which has been indicated in Fig. 6B1. However, the surface of the membrane sintered at $1075^{\circ} \mathrm{C}$ showed a lower $R_{a}$ value of $0.336 \mu \mathrm{m}$ due to the more rapid effective migration of surface grains by diffusion, leading to a smoother membrane surface. A further increase of sintering temperature to $1100^{\circ} \mathrm{C}$ caused the membrane surface to become very smooth and almost dense with very few pores (Fig. 6D2), resulting in the lowest $R_{a}$ value of $0.303 \mu \mathrm{m}$ (Fig. 7D).

\subsubsection{Radial shrinkage and bending properties of membranes}

Figure 8 illustrates the overall morphology of CHFM before and after sintering at various temperatures. As compared to the hollow fiber precursor, the overall diameter of CHFM decreased after sintering due to the thermal/oxidative decomposition of the membrane precursor during the sintering process. Moreover, the radial shrinkage of CHFM also increased with increasing sintering temperature. Based on Table 6, C-S1 experienced a radial shrinkage of $14.4 \%$ compared to that of the hollow fiber precursor. The radial shrinkage of CHFM increased to $16.0 \%$ and $18.2 \%$ for C-S2 and C-S3, respectively. The radial shrinkage of $\mathrm{CHFM}$ was the highest when the sintering temperature was increased to $1100^{\circ} \mathrm{C}$, with a value of $22.9 \%$ due to the rapid membrane densification as indicated in Fig. 6D.

The bending strength of CHFM increased with the increase in sintering temperature (Table 6). The bending strength was the lowest for the CHFM sintered at $1025^{\circ} \mathrm{C}$ with a value of $75.9 \mathrm{MPa}$. Based on Fig. 6A1, the neck formation only occurred among the small particles, whereas the large particles had yet to undergo any observable neck growth, which afflicted the mechanical properties of CHFM. The grain growth started to occur at the sintering temperature of $1050^{\circ} \mathrm{C}$, which led to an increase in the bending 
strength to $98.1 \mathrm{MPa}$. A further increase of sintering temperature to $1075^{\circ} \mathrm{C}$ promoted the densification of the membrane, consequently provided an enhanced bending strength. C-S4 demonstrated the highest bending strength of 112.5 MPa due to the most densified membrane structure (Fig. 6D1 and D2), which bestowed the membrane with enhanced mechanical properties.

Table 6

Radial shrinkage and bending strength of the CHFMs after sintering at different temperatures $(n=3)$

\begin{tabular}{|lll|}
\hline Membrane & Radial shrinkage (\%) & Bending strength (MPa) \\
\hline C-S1 & $7.2 \pm 0.9$ & $75.9 \pm 4.0$ \\
C-S2 & $8.6 \pm 0.7$ & $98.1 \pm 1.8$ \\
C-S3 & $18.2 \pm 0.2$ & $102.7 \pm 1.7$ \\
C-S4 & $22.9 \pm 0.4$ & $112.5 \pm 1.8$ \\
\hline
\end{tabular}

\subsubsection{Overall pore size distribution, porosity, tortuosity, and permeation performance}

The overall PSD, porosity, and tortuosity factor of the CHFM sintered at different temperatures were determined via MIP. Based on Fig. 9A, the PSD curves show bimodal peaks which indicated the asymmetric structure of finger-like macro-voids and sponge-like layers. For C-S1, the two significant peaks at $1.05 \mu \mathrm{m}$ and $2.09 \mu \mathrm{m}$ were attributed to the sponge-like pores and finger-like macro-voids. The pore size of the sponge-like layer increased from $1.05 \mu \mathrm{m}$ to $1.33 \mu \mathrm{m}$ with increasing sintering temperature from $1025^{\circ} \mathrm{C}$ to $1100^{\circ} \mathrm{C}$. The increase in sintering temperature accelerated the neck formation between the large grains, which prevented the large pore from collapsing [7]. Simultaneously, the small pores were eliminated due to the dissolution of small grains in the liquid $\mathrm{K}_{2} \mathrm{O}$ to reprecipitate on the larger grains. A similar trend was also observed by Li et al. [7] who reported that the pore size of the alumina-mullite composite CHFM increased with increasing sintering temperature. Based on the PSD results, the CHFM developed in this study can be categorized as microfiltration membranes. Hence, these membranes can be used for microfiltration applications, such as oil/water separation and removal of bacteria from water.

C-S1 exhibited a high porosity of $39.2 \%$ and the porosity gradually decreased to $36.5 \%$ for C-S2 (Fig. 9B). A drastic drop in porosity occurred when the sintering temperature was $1075^{\circ} \mathrm{C}$. C-S 4 demonstrated the lowest porosity of $16.4 \%$ due to the densest membrane structure after sintering. From Fig. 9B, it could be seen that the tortuosity factor increased for the CHFM sintered at higher temperatures which suggested that higher sintering temperature induced the formation of more complex pore channels. An abrupt surge in tortuosity factor from 2.06 to 2.14 was observed when the sintering temperature was increased from 1 $050^{\circ} \mathrm{C}$ to $1075^{\circ} \mathrm{C}$. The vigorous neck growth and grain diffusion phenomena during the sintering process altered the pore channels which resulted in more tortuous pore structures. 
As shown in Fig. 10, the PWF of the CHFM was influenced by the membrane porosity and tortuosity. The low porosity would limit the passage of the mass transfer across the membrane, while high tortuosity would create a long path and high resistance against the mass transport. C-S1, which had the most porous membrane structure and the lowest tortuosity, demonstrated the highest flux of $289.6 \mathrm{~L} / \mathrm{m}^{2} \mathrm{~h}$ at 2 bar operating pressure. Meanwhile, grain growth started to occur at the sintering temperature of 1 $050^{\circ} \mathrm{C}$, which reduced the membrane porosity and increased the tortuosity. As a result, the PWF performance of C-S2 was afflicted and reduced drastically to $123.2 \mathrm{~L} / \mathrm{m}^{2} \mathrm{~h}$. The PWF further dropped to $59.4 \mathrm{~L} / \mathrm{m}^{2} \mathrm{~h}$ and $12.1 \mathrm{~L} / \mathrm{m}^{2} \mathrm{~h}$ for the $\mathrm{CHFM}$ sintered at $1075^{\circ} \mathrm{C}$ and $1100^{\circ} \mathrm{C}$, respectively. The findings of the PWF performance suggested that the CHFM sintered at $1050^{\circ} \mathrm{C}$ exhibited the optimum properties in terms of excellent mechanical strength of close to $100 \mathrm{MPa}$ with high PWF.

\subsection{Properties comparison with other alternative ceramic hollow fiber membranes}

Table 7 summarizes the properties of POFA-derived CHFM and other alternative CHFM reported in the literature. The POFA-derived CHFM developed in this study showed relatively low PWF compared to alternative counterparts mainly due to the lower membrane porosity. Moreover, it could also be observed that the POFA-derived CHFM obtained high bending strengths of $\geq 75.9 \mathrm{MPa}$, which was higher than the silica-based CHFM reported in the literature, such as sugarcane bagasse ash, rice husk ash, corncob ash, ball clay, waste fly ash, kaolin, natural zeolite and corncob ash/metakaolin (Table 7). Interestingly, the POFA-derived CHFM also acquired such high bending strengths at comparatively low sintering temperatures than the high-strength bauxite and metakaolin CHFM, which required higher sintering temperatures of $\geq 1200^{\circ} \mathrm{C}$ to attain high bending strength. For POFA-derived CHFM, the relatively low requirement of sintering temperature was attributed to the notable $\mathrm{K}_{2} \mathrm{O}$ content $(6.4 \mathrm{wt} \%)$ that acted as an intrinsic sintering aid. At elevated sintering temperature, the liquid phase $\mathrm{K}_{2} \mathrm{O}$ promoted the neck and grain growth phenomena which contributed to lower the sintering temperature [42]. The relatively low sintering temperature of POFA-derived CHFM is advantageous in minimizing the energy consumption and sintering duration, which could make it more economically attractive compared to its CHFM counterparts. 
Table 7

Comparison between the properties of POFA-derived CHFMs with other alternative CHFMs from literature

\begin{tabular}{|c|c|c|c|c|c|c|}
\hline Membrane & $\begin{array}{l}\text { Sintering } \\
\text { temperature } \\
\text { ('C) }\end{array}$ & $\begin{array}{l}\text { Pore } \\
\text { size } \\
(\mu \mathrm{m})\end{array}$ & $\begin{array}{l}\text { Porosity } \\
\text { (\%) }\end{array}$ & $\begin{array}{l}\text { Bending } \\
\text { strength } \\
\text { (MPa) }\end{array}$ & $\begin{array}{l}\text { PWF } \\
\left(L / m^{2} h\right)\end{array}$ & Reference \\
\hline POFA & $1025-1100$ & $\begin{array}{l}1.05- \\
2.09\end{array}$ & $\begin{array}{l}16.4- \\
39.2\end{array}$ & $75.9-112.5$ & $\begin{array}{l}12.0- \\
289.6\end{array}$ & This work \\
\hline Bauxite & $1200-1350$ & $0.7-0.9$ & - & $24.0-188.3$ & - & [7] \\
\hline Metakaolin & $1200-1500$ & $\begin{array}{l}0.007- \\
0.15\end{array}$ & $\begin{array}{l}9.2- \\
27.2\end{array}$ & 117.7-187.9 & - & [48] \\
\hline Kaolin/alumina & 1400 & 0.29 & 61.8 & 87.4 & - & [49] \\
\hline $\begin{array}{l}\text { Sugarcane } \\
\text { bagasse ash }\end{array}$ & $1000-1300$ & $\begin{array}{l}1.85- \\
3.87\end{array}$ & $\begin{array}{l}42.3- \\
68.3\end{array}$ & $44.1-68.1$ & $\begin{array}{l}457- \\
540\end{array}$ & [11] \\
\hline Rice husk ash & $1200-1400$ & $\begin{array}{l}1.63- \\
3.70\end{array}$ & $\begin{array}{l}62.1- \\
66.3\end{array}$ & $42.2-90.3$ & $\begin{array}{l}300- \\
330\end{array}$ & [9] \\
\hline Corncob ash & $800-1100$ & - & - & $9.9-31.4$ & - & [50] \\
\hline Ball clay & 1250 & 0.61 & 50.5 & 55.8 & 1286 & [10] \\
\hline Alumina dross & $1250-1300$ & $\begin{array}{l}0.49- \\
0.55\end{array}$ & $\begin{array}{l}4.2- \\
25.0\end{array}$ & 25.7 & $\begin{array}{l}17.6- \\
84.0\end{array}$ & [51] \\
\hline $\begin{array}{l}\text { Alumina/waste } \\
\text { of quartzite }\end{array}$ & $1100-1500$ & - & $\begin{array}{l}6.6- \\
27.3\end{array}$ & $25.0-82.6$ & $\begin{array}{l}4.4- \\
263.2\end{array}$ & [52] \\
\hline Waste fly ash & $1150-1400$ & - & - & $13.0-128.0$ & $\begin{array}{l}51.0- \\
478.0\end{array}$ & [53] \\
\hline Kaolin & $1200-1500$ & $\begin{array}{l}0.21- \\
1.51\end{array}$ & $\begin{array}{l}7.8- \\
69.1\end{array}$ & $5.6-61.9$ & - & [8] \\
\hline Natural zeolite & $900-1150$ & - & - & $10.3-63.5$ & $\begin{array}{l}228.1- \\
828.1\end{array}$ & [54] \\
\hline $\begin{array}{l}\text { Corncob } \\
\text { ash/metakaolin }\end{array}$ & 1200 & 10.38 & 62.0 & 41.6 & 1159 & [34] \\
\hline
\end{tabular}

\section{Conclusions}

In this study, low-cost green CHFM were successfully fabricated from POFA and designed in a predetermined manner via phase inversion-based extrusion/sintering techniques for water filtration applications. The morphology structures of CHFM were studied by manipulating the phase inversion parameters such as suspension viscosity, air gap distance, and bore fluid flow rate. Particularly, the fingerlike macro-void structure diminished when the suspension viscosity increased due to greater resistance and friction against the invading micro-streams. The length of the finger-like structure could be increased by increasing the air gap distance as it provided longer contact time between the hollow fibers with the 
bore fluid before the fibers were being submerged into the coagulant bath. In addition, higher air gap distance also caused the hollow fiber to experience larger circumferential stress caused by the bore fluid, as well as greater longitudinal stress by the gravitational pull when falling from the spinneret into the coagulant bath, resulting in the thinner wall and smaller fiber diameter. Moreover, the bore fluid flow rate could also affect the morphology of CHFM. A lower bore fluid flow rate resulted in the deformation of the fiber lumen, whereas a higher bore fluid flow rate led to a larger lumen diameter due to larger hydrodynamic force against the ceramic suspension during spinning. It was also found that the membrane porosity decreased while the membrane pore size and tortuosity increased with an increase in sintering temperature. Due to lower porosity and higher tortuosity, the CHFM sintered at higher temperatures demonstrated lower PWF. The CHFM fabricated with a POFA loading of $55 \mathrm{wt} \%$, air gap distance of $5 \mathrm{~cm}$, bore fluid flow rate of $9 \mathrm{~mL} / \mathrm{min}$ and sintering temperature of $1050^{\circ} \mathrm{C}$ showed the optimum properties for water filtration applications with an excellent mechanical strength of $98.1 \mathrm{MPa}$ and high PWF of $123.2 \mathrm{~L} / \mathrm{m}^{2} \mathrm{~h}$.

Lastly, the properties of the POFA-derived CHFM were compared with other alternative CHFM reported in the literature. The POFA-derived CHFMs demonstrated excellent bending strengths of $>75 \mathrm{MPa}$ at comparatively low sintering temperatures. This was attributed to the significant amount of $\mathrm{K}_{2} \mathrm{O}$ in the POFA composition which acted as the low melting point sintering aid. The relatively low sintering temperature of POFA-derived CHFM would reduce the energy consumption and sintering duration, which could potentially be more economically attractive compared to their ceramic counterparts.

\section{Declarations}

\section{Acknowledgments}

The authors gratefully acknowledge the financial support from the Ministry of Education Malaysia under the Higher Institution Centre of Excellence Scheme (Project Number: R.J090301.7846.4J193) and LongTerm Research Grant Scheme (Project Number: R.J130000.7809.4L895), and also Universiti Teknologi Malaysia under the Transdisciplinary Research Grant (Project number: Q.J130000.3509.05G75), Malaysia Research University Network (MRUN) Grant (Project number: R.J130000.7809.4L867), Higher Institution Centre of Excellence (HICoE) Research Grant (Project number: R.J090301.7851.4J426), and UTM GUP Tier 1 (Project number: Q.J130000.2546.19H18). The authors would also like to thank the Research Management Centre (RMC), Universiti Teknologi Malaysia for the technical support and services provided.

\section{References}

1. Abbasi M, Salahi A, Mirfendereski M et al (2010) Dimensional analysis of permeation flux for microfiltration of oily wastewaters using mullite ceramic membranes. Desalination 252:113-119 
2. Wang J-W, Li L, Zhang J-W et al (2016) $\beta$-Sialon ceramic hollow fiber membranes with high strength and low thermal conductivity for membrane distillation. J Eur Ceram Soc 36:59-65

3. Tai ZS, Abd Aziz MH, Othman MHD et al. Ceramic membrane distillation for desalination. Sep Purif $\operatorname{Rev} 2019,1-40$

4. Moch I (2010) Hollow-fiber membranes. In: Desalination and Water Resources: Membrane Processes. Eolss Publishers Co. Ltd., Singapore, pp 284-318

5. García-Fernández L, Wang B, García-Payo MC et al. Morphological design of alumina hollow fiber membranes for desalination by air gap membrane distillation. Desalination 2017, 226-240

6. Fang H, Gao JF, Wang HT et al (2012) Hydrophobic porous alumina hollow fiber for water desalination via membrane distillation process. J Membrane Sci 403-404:41-46

7. Li L, Chen M, Dong Y et al (2016) A low-cost alumina-mullite composite hollow fiber ceramic membrane fabricated via phase-inversion and sintering method. J Eur Ceram Soc 36:2057-2066

8. Hubadillah SK, Othman MHD, Rahman MA et al (2020) Preparation and characterization of inexpensive kaolin hollow fibre membrane (KHFM) prepared using phase inversion/sintering technique for the efficient separation of real oily wastewater. Arab J Chem 1:2349-2367

9. Hubadillah SK, Othman MHD, Ismail AF et al (2018) Fabrications and applications of low cost ceramic membrane from kaolin: A comprehensive review. Ceram Int 44:10498-10509

10. Abd Aziz MH, Othman MHD, Hashim NA et al (2019) Fabrication and characterization of mullite ceramic hollow fiber membrane from natural occurring ball clay. Appl Clay Sci 177:51-62

11. Jamalludin MR, Harun Z, Othman MHD et al (2018) Morphology and property study of green ceramic hollow fiber membrane derived from waste sugarcane bagasse ash (WSBA). Ceram Int 44:1845018461

12. Tai ZS, Hubadillah SK, Othman MHD et al (2019) Influence of pre-treatment temperature of palm oil fuel ash on the properties and performance of green ceramic hollow fiber membranes towards oil/water separation application. Sep Purif Technol 222:264-277

13. Information on https://www.researchandmarkets.com/research/bzhdpg/global_palm_oil?w = 12

14. Information on https://palmoilalliance.eu/more-facts/

15. Abdulhameed MD, Othman MHD, Ismail AF et al (2017) Carbon dioxide capture using a superhydrophobic ceramic hollow fibre membrane for gas-liquid contacting process. J Clean Prod 140:1731-1738

16. Shenvi SS, Isloor AM, Ahmad AL et al (2016) Influence of palm oil fuel ash, an agro-industry waste on the ultrafiltration performance of cellulose acetate butyrate membrane. Desalin Water Treat 57:26414-26426

17. Bonassa G, Schneider LT, Alves HJ et al (2016) Sugarcane bagasse ash for waste cooking oil treatment applications. J Environ Chem Eng 4:4091-4099

18. Kingsbury BFK, Li K (2009) A morphological study of ceramic hollow fibre membranes. J Membrane Sci 328:134-140 
19. Paiman SH, Rahman MA, Othman MHD et al (2015) Morphological study of yttria-stabilized zirconia hollow fibre membrane prepared using phase inversion/sintering technique. Ceram Int 41:1254312553

20. Lee M, Wang B, Li K (2016) New designs of ceramic hollow fibres toward broadened applications. J Membrane Sci 503:48-58

21. Fung Y-LE, Wang H (2014) Nickel aluminate spinel reinforced ceramic hollow fibre membrane. J Membrane Sci 450:418-424

22. Xu G, Wang K, Zhong Z et al (2014) SiC nanofiber reinforced porous ceramic hollow fiber membranes. J Mater Chem A 2:5841-5846

23. Yusof MSM, Othman MHD, Mustafa A et al (2018) Feasibility study of cadmium adsorption by palm oil fuel ash (POFA)-based low-cost hollow fibre zeolitic membrane. Environ Sci Pollut R 25:2164421655

24. Tai ZS, Othman MHD, Hubadillah SK et al (2018) Low cost palm oil fuel ash based ceramic membranes for oily water separation. Mal J Fund Appl Sci 14:419-424

25. Chen Z, Li J, Liu C et al (2019) Preparation of high solid loading and low viscosity ceramic slurries for photopolymerization-based 3D printing. Ceram Int 45:11549-11557

26. Liu W, Lv L, Li Y et al (2017) Effects of slurry composition on the properties of 3 - 1 type porous PZT ceramics prepared by ionotropic gelation. Ceram Int 43:6542-6547

27. Zhang K, He R, Xie C et al (2019) Photosensitive $\mathrm{ZrO}_{2}$ suspensions for stereolithography. Ceram Int 45:12189-12195

28. Wan W, Yang J, Zeng J et al (2014) Aqueous gelcasting of silica ceramics using DMAA. Ceram Int 40:1257-1262

29. Liu T, Ren C, Fang S et al (2014) Microstructure tailoring of the nickel oxide-yttria-stabilized zirconia hollow fibers toward high-performance microtubular solid oxide fuel cells. ACS Appl Mater Interfaces 6:18853-18860

30. Othman MHD, Wu Z, Droushiotis N et al (2010) Morphological studies of macrostructure of Ni-CGO anode hollow fibres for intermediate temperature solid oxide fuel cells. J Membrane Sci 360:410417

31. Li K (2007) Ceramic Membranes for Separation and Reaction. John Wiley \& Sons Ltd, Great Britain

32. Ranieri G, Mazzei R, Wu Z et al (2016) Use of a ceramic membrane to improve the performance of two-separate-phase biocatalytic membrane reactor. Molecules 21:345

33. Hubadillah SK, Othman MHD, Matsuura T et al (2018) Green silica-based ceramic hollow fiber membrane for seawater desalination via direct contact membrane distillation. Sep Purif Technol 205:22-31

34. Kamarudin NH, Harun Z, Othman MHD et al (2020) Waste environmental sources of metakaolin and corn cob ash for preparation and characterisation of green ceramic hollow fibre membrane $(h-\mathrm{MCa})$ for oil-water separation. Ceram Int 46:1512-1525 
35. Li H, Liu G, Yan C (2014) Content and distribution of trace elements and polycyclic aromatic hydrocarbons in fly ash from a coal-fired CHP plant. Aerosol Air Qual Res 14:1179-1188

36. Ke XB, Zheng ZF, Liu HW et al (2008) High-flux ceramic membranes with a nanomesh of metal oxide nanofibers. J Phys Chem B 112:5000-5006

37. Ke XB, Zhu HY, Gao XP et al (2007) High-performance ceramic membranes with a separation layer of metal oxide nanofibers. Adv Mater 19:785-790

38. Chung T-S, Hu X (1997) Effect of air-gap distance on the morphology and thermal properties of polyethersulfone hollow fibers. J Appl Polym Sci 66:1067-1077

39. Khayet M (2003) The effects of air gap length on the internal and external morphology of hollow fiber membranes. Chem Eng Sci 58:3091-3104

40. Bonyadi S, Chung TS, Krantz WB (2007) Investigation of corrugation phenomenon in the inner contour of hollow fibers during the non-solvent induced phase-separation process. J Membrane Sci 299:200-210

41. Fang $\mathrm{S}$, Wang S, Brinkman KS et al (2014) A sinteractive $\mathrm{Ni}-\mathrm{BaZr}_{0.8} \mathrm{Y}_{0.2} \mathrm{O}_{3-\delta}$ composite membrane for hydrogen separation. J Mater Chem A 2:5825-5833

42. Vu H, Nguyen D, Fisher JG et al (2013) CuO-based sintering aids for low temperature sintering of $\mathrm{BaFe}_{12} \mathrm{O}_{19}$ ceramics. J Asian Ceram Soc 1:170-177

43. German RM, Suri P, Park SJ (2009) Review: liquid phase sintering. J Mater Sci 44:1-39

44. Kang S-JL (2005) Sintering: Densification, Grain Growth \& Microstructure. Butterworth-Heinemann, Oxford: Elsevier

45. Gessinger GH, Fischmeister HF (1972) A modified model for the sintering of tungsten with nickel additions. J Less Common Met 27:129-141

46. Gessinger GH, Fischmeister HF, Lukas HL (1973) A model for second-stage liquid-phase sintering with a partially wetting liquid. Acta Met 21:715-724

47. Talebi T, Haji M, Raissi B (2010) Effect of sintering temperature on the microstructure, roughness and electrochemical impedance of electrophoretically deposited YSZ electrolyte for SOFCs. Int J Hydrog Energy 35:9420-9426

48. Hubadillah SK, Othman MHD, Harun Z et al (2016) Effect of fabrication parameters on physical properties of metakaolin-based ceramic hollow fibre membrane (CHFM). Ceram Int 42:15547-15558

49. Abdulhameed MA, Othman MHD, Joda HNAA et al (2017) Fabrication and characterization of affordable hydrophobic ceramic hollow fibre membrane for contacting processes. J Adv Ceram 6:330-340

50. Kamarudin NH, Harun Z, Othman MHD et al (2018) Preliminary characterization of corn cob ash as an alternative material for ceramic hollow fiber membrane (CHFM/CCA). Int J Eng Trans B: Appl 31:1389-1397

51. Aziz MHA, Othman MHD, Hashim NA et al (2019) Pretreated aluminium dross waste as a source of inexpensive alumina-spinel composite ceramic hollow fibre membrane for pretreatment of oily saline 
produced water. Ceram Int 45:2069-2078

52. Oliveira SSL, Oliveira SSL, Ferreira RdSB et al (2019) Development o hollow fiber membranes with alumina and waste of quartzite. Mater Res 22:1-7

53. Zulkifli SNA, Mustafa A, Othman MHD et al (2019) Characteristic properties of ceramic membrane derived from fly ash with different loadings and sintering temperature. Mal J Fund Appl Sci 15:414420

54. Adam MR, Othman MHD, Puteh MH et al (2020) Impact of sintering temperature and $\mathrm{pH}$ of feed solution on adsorptive removal of ammonia from wastewater using clinoptilolite based hollow fibre ceramic membrane. J Water Process Eng 33:101063

\section{Figures}
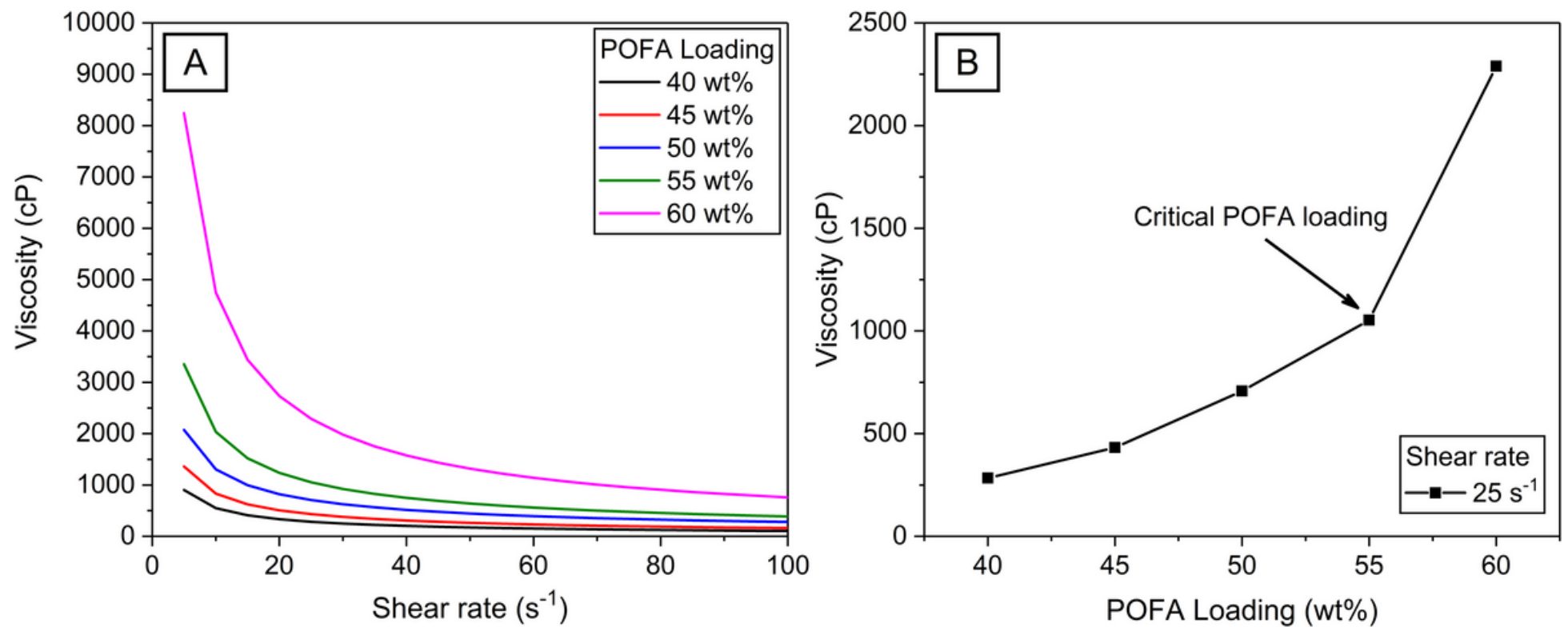

Figure 1

Rheological properties of POFA suspensions: (A) viscosity versus shear rate; (B) viscosity versus POFA loading at the shear rate of $25 \mathrm{~s}-1$ 


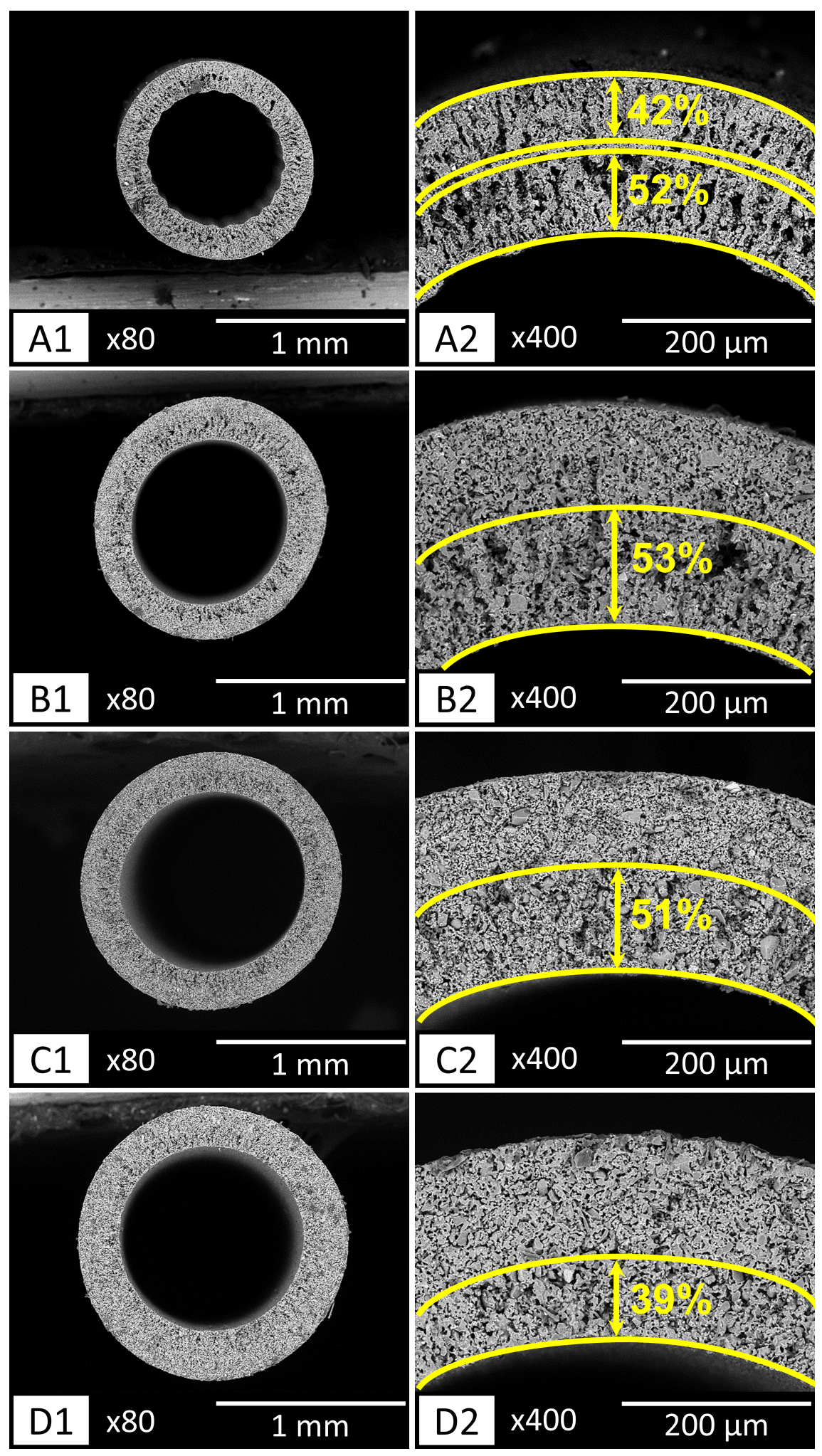

Figure 2

(1) Overall morphology (80x magnification) and (2) cross-sections (400x magnification) of (A) C-P40, (B) C-P45, (C) C-P50 and (D) C-P55 where the area bounded by yellow lines refers to finger-like structure (air gap distance: $5 \mathrm{~cm}$; bore fluid flow rate: $9 \mathrm{~mL} / \mathrm{min}$; sintering temperature: $1050^{\circ} \mathrm{C}$ ) 


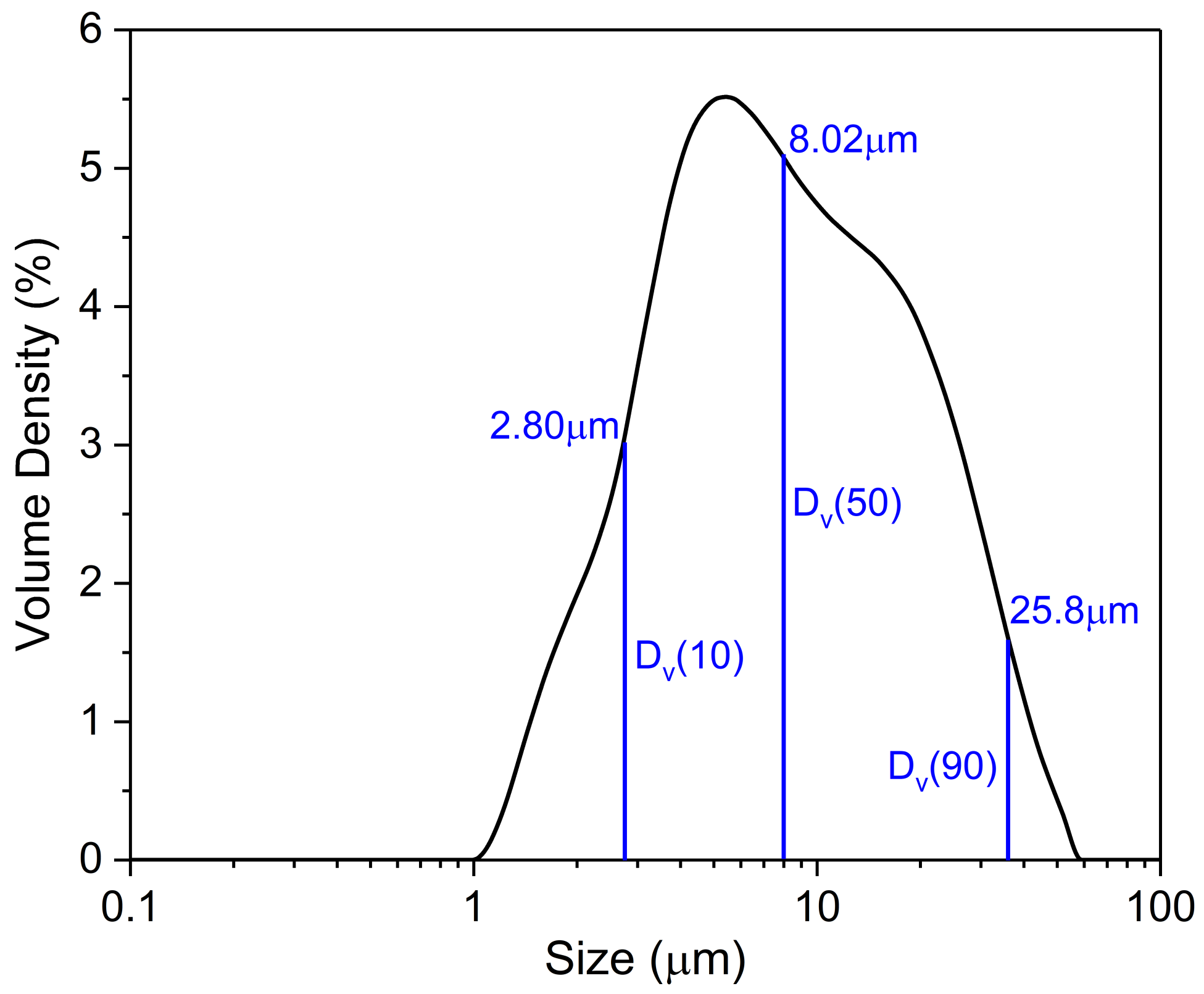

Figure 3

Particle size distribution of POFA 


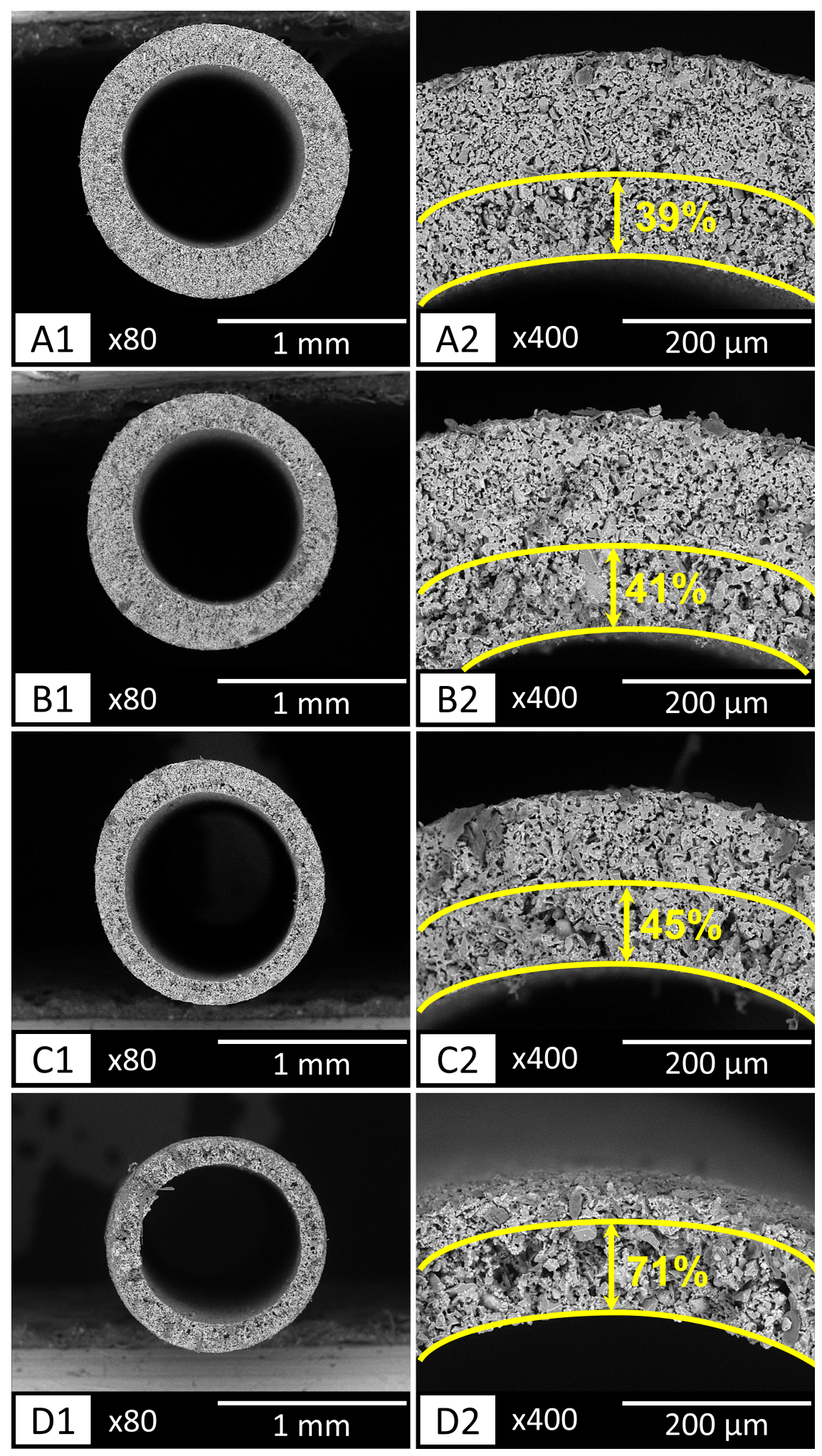

Figure 4

(1) Overall morphology (80x magnification) and (2) cross-sections (400x magnification) of (A) C-A5, (B) C-A7, (C) C-A10 and (D) C-A15 where the area bounded by yellow lines refers to finger-like structure (POFA loading: $55 \mathrm{wt} \%$; bore fluid flow rate: $9 \mathrm{~mL} / \mathrm{min}$; sintering temperature: $1050^{\circ} \mathrm{C}$ ) 


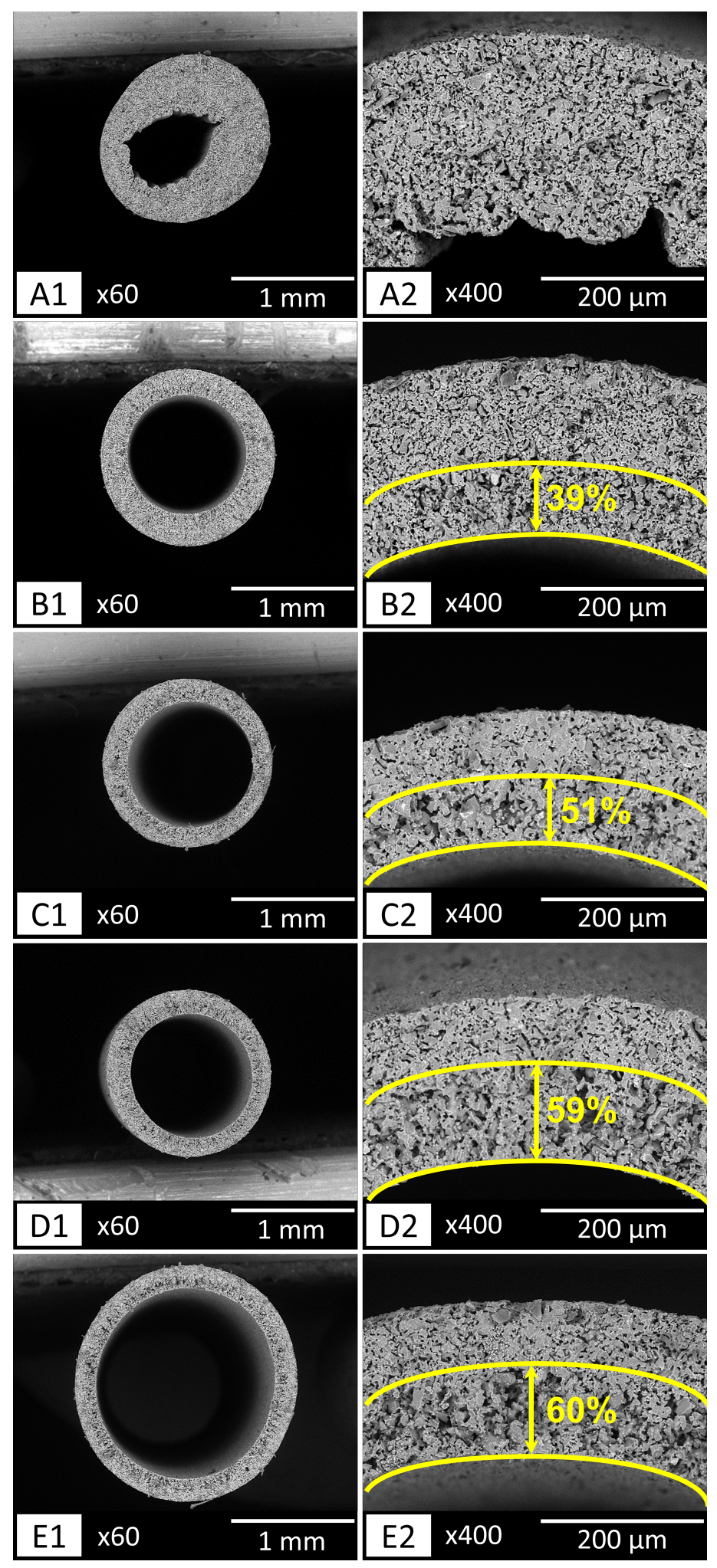

Figure 5

(1) Overall morphology (60x magnification) and (2) cross-sections (400x magnification) of (A) C-B6, (B) C-B9, (C) C-B12, (D) C-B15 and (E) C-B20 where the area bounded by yellow lines refers to finger-like structure (POFA loading: $55 \mathrm{wt} \%$; air gap distance: $5 \mathrm{~cm}$; sintering temperature: $1050^{\circ} \mathrm{C}$ ) 


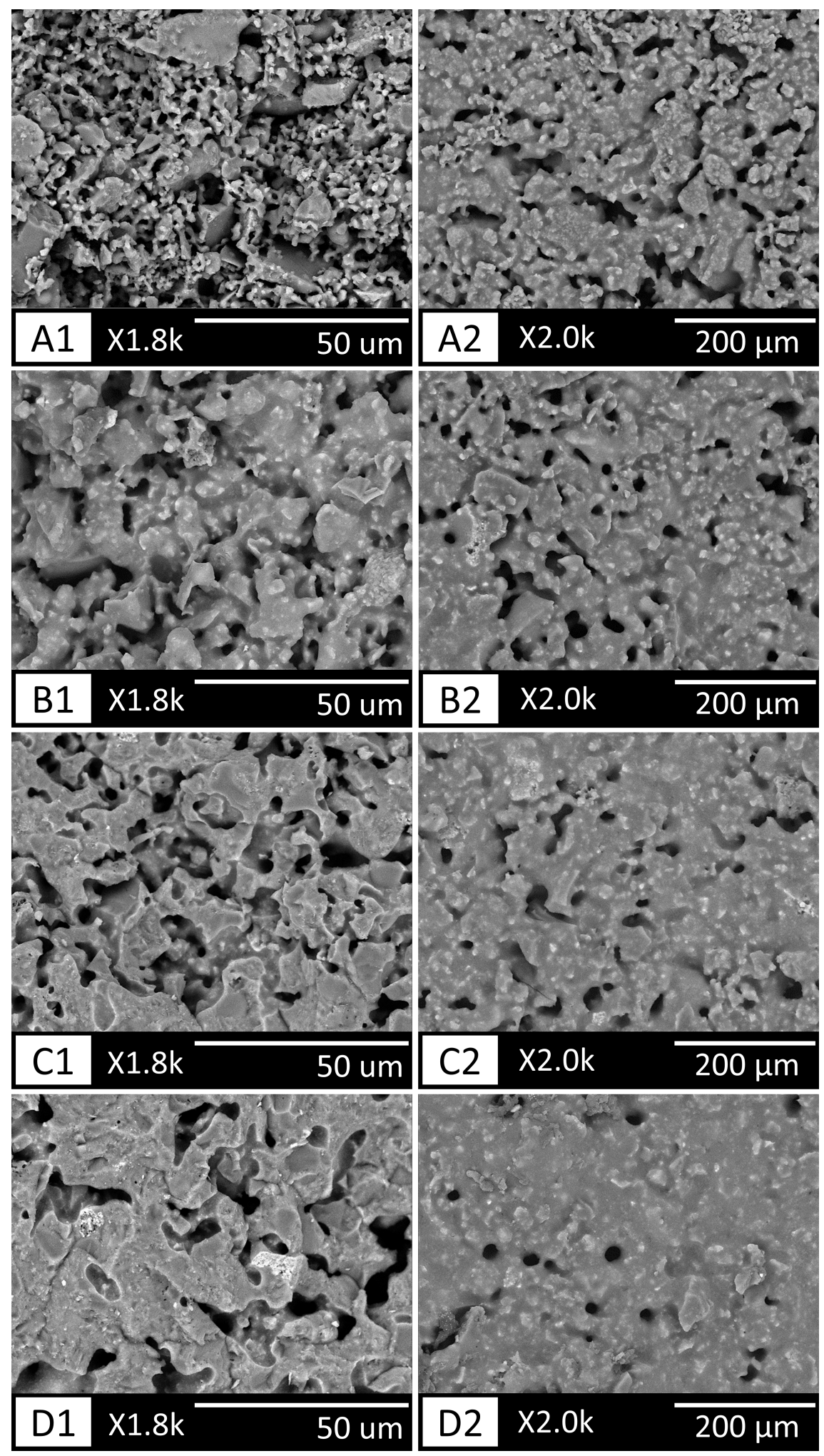

Figure 6

(1) Cross-sections (1,800x magnification) and (2) outer surface (2,000x magnification) of (A) C-S1, (B) CS2, (C) C-S3 and (D) C-S4 (POFA loading: $55 \mathrm{wt} \%$; air gap distance: $5 \mathrm{~cm}$; bore fluid flow rate: $9 \mathrm{~mL} / \mathrm{min}$ ) 


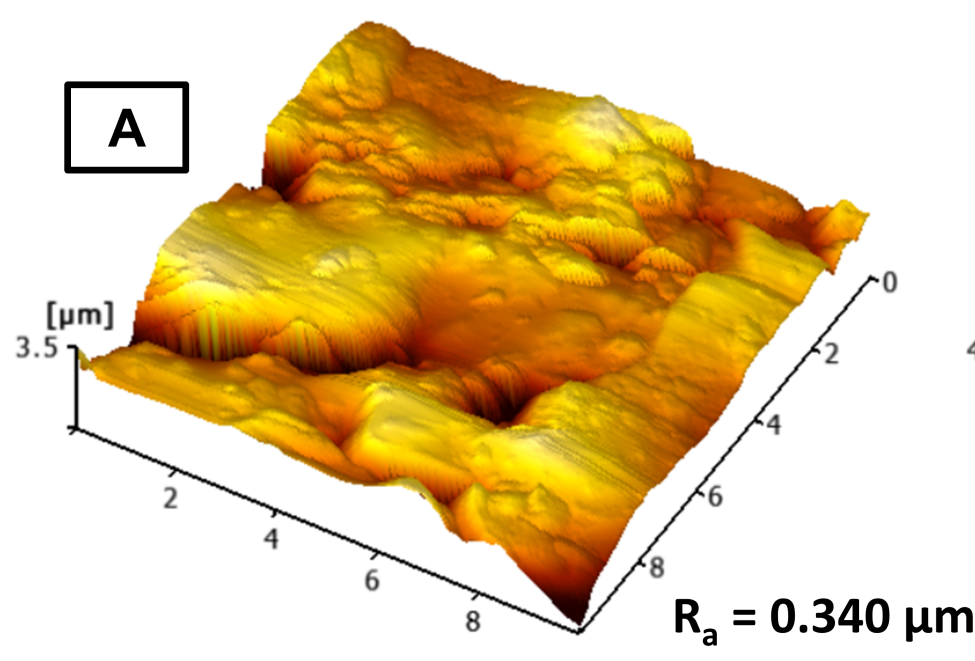

[ $\mu \mathrm{m}]$

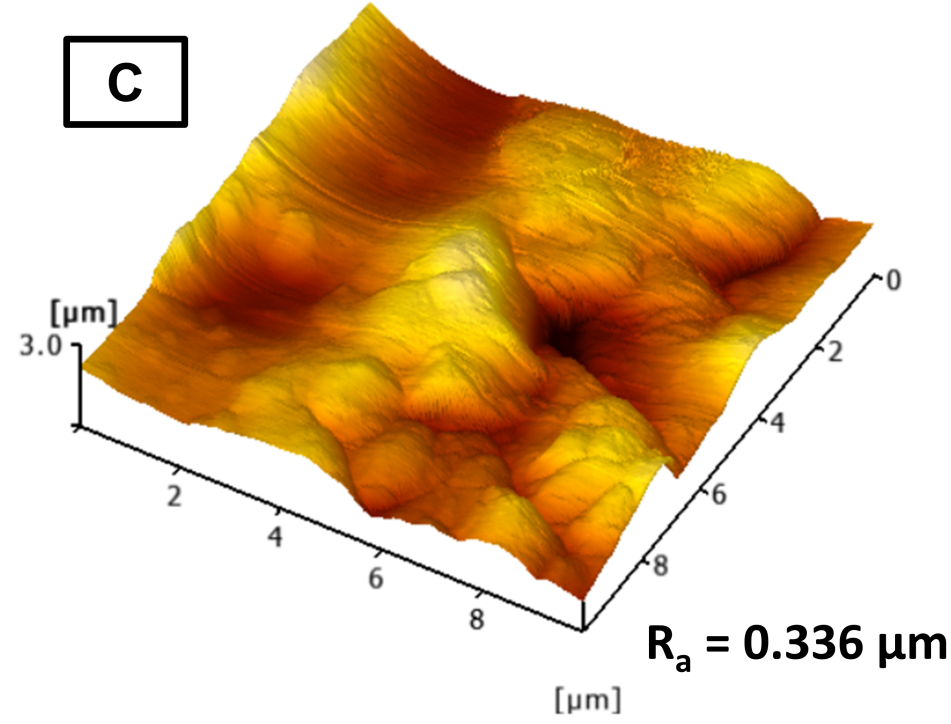

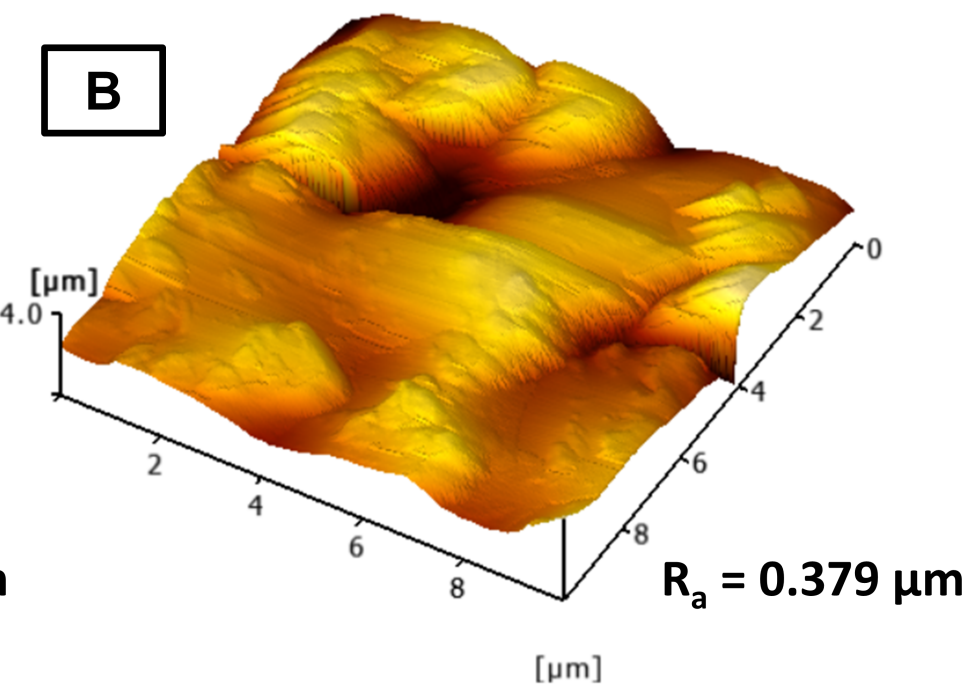

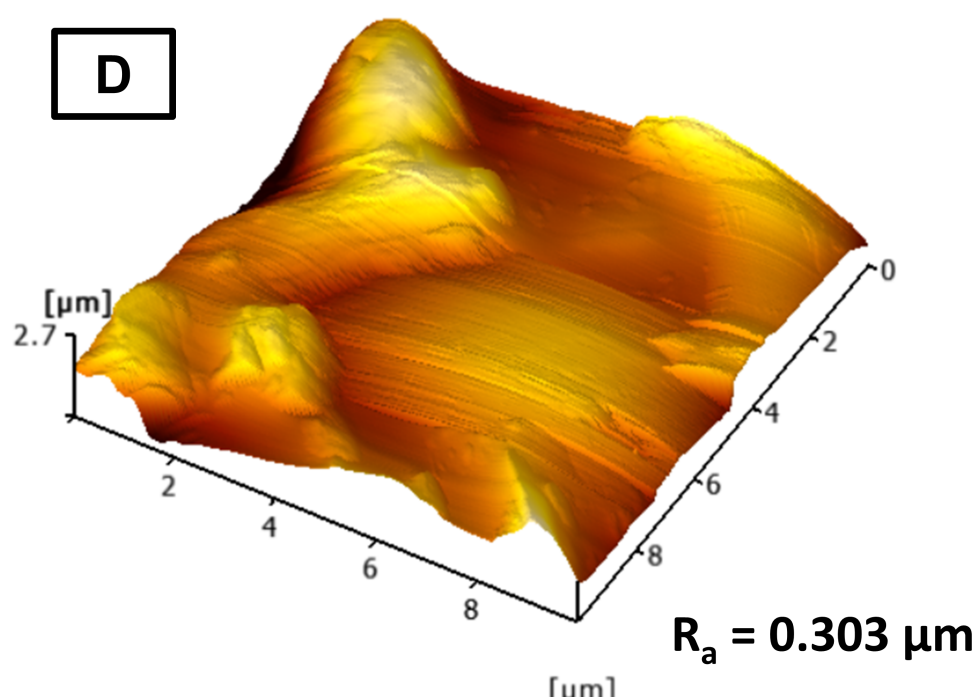

Figure 7

AFM images of the outer surface of (A) C-S1, (B) C-S2, (C) C-S3 and (D) C-S4 

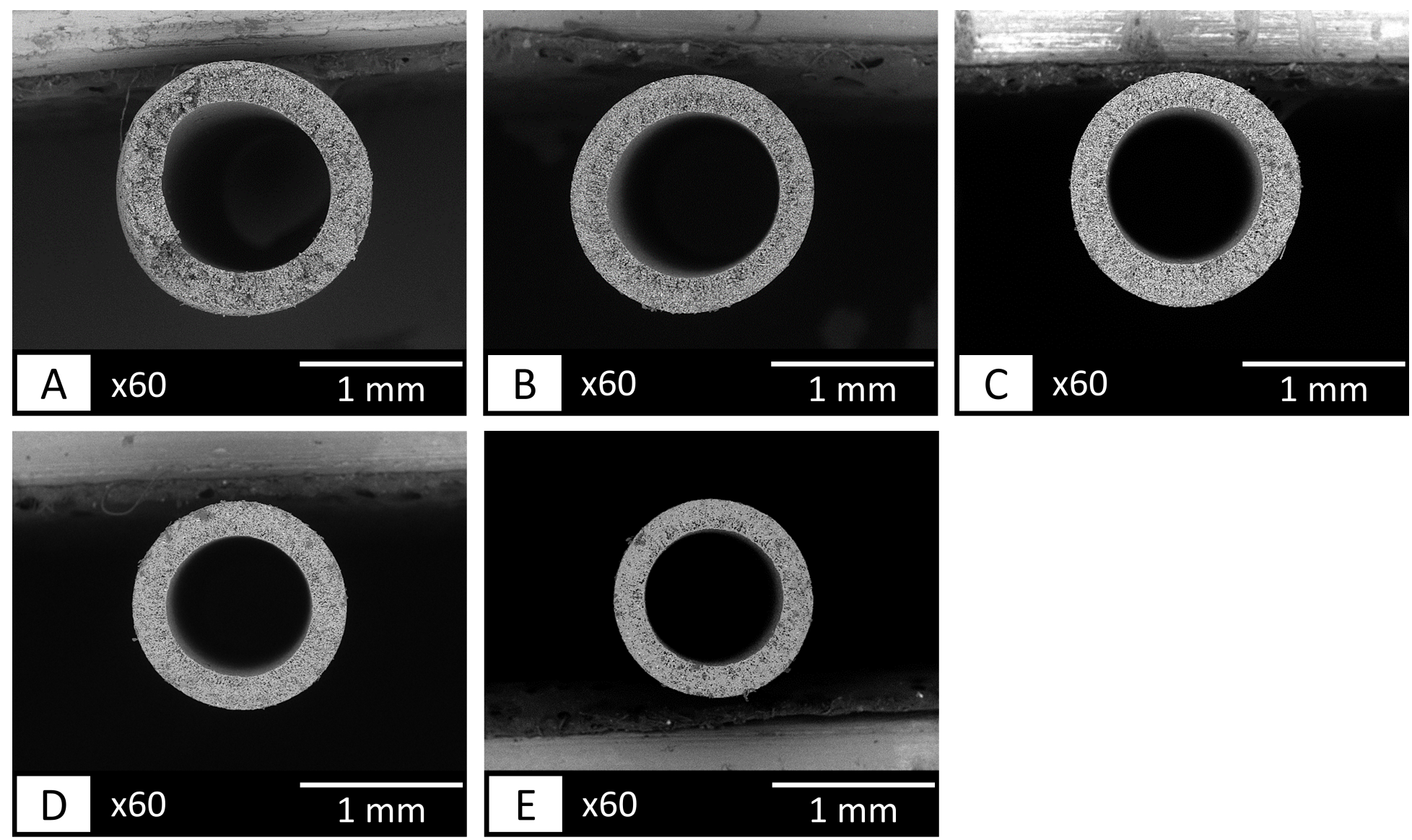

Figure 8

Overall morphology (60x magnification) of (A) hollow fiber precursor, (B) C-S1, (C) C-S2, (D) C-S3 and (E) C-S4 (POFA loading: $55 \mathrm{wt} \%$; air gap distance: $5 \mathrm{~cm}$; bore fluid flow rate: $9 \mathrm{~mL} / \mathrm{min}$ )
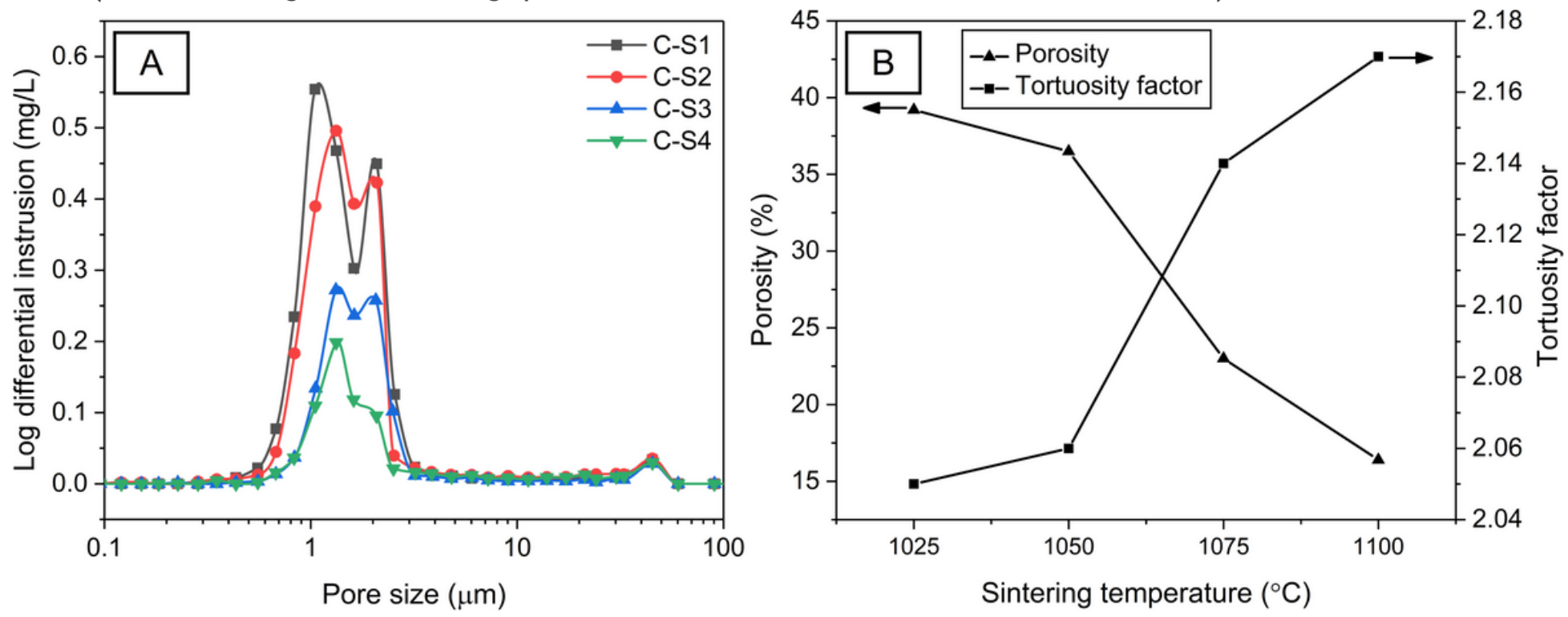

Figure 9

(A) PSD and (B) porosity and tortuosity factor of the CHFM sintered at different temperatures 


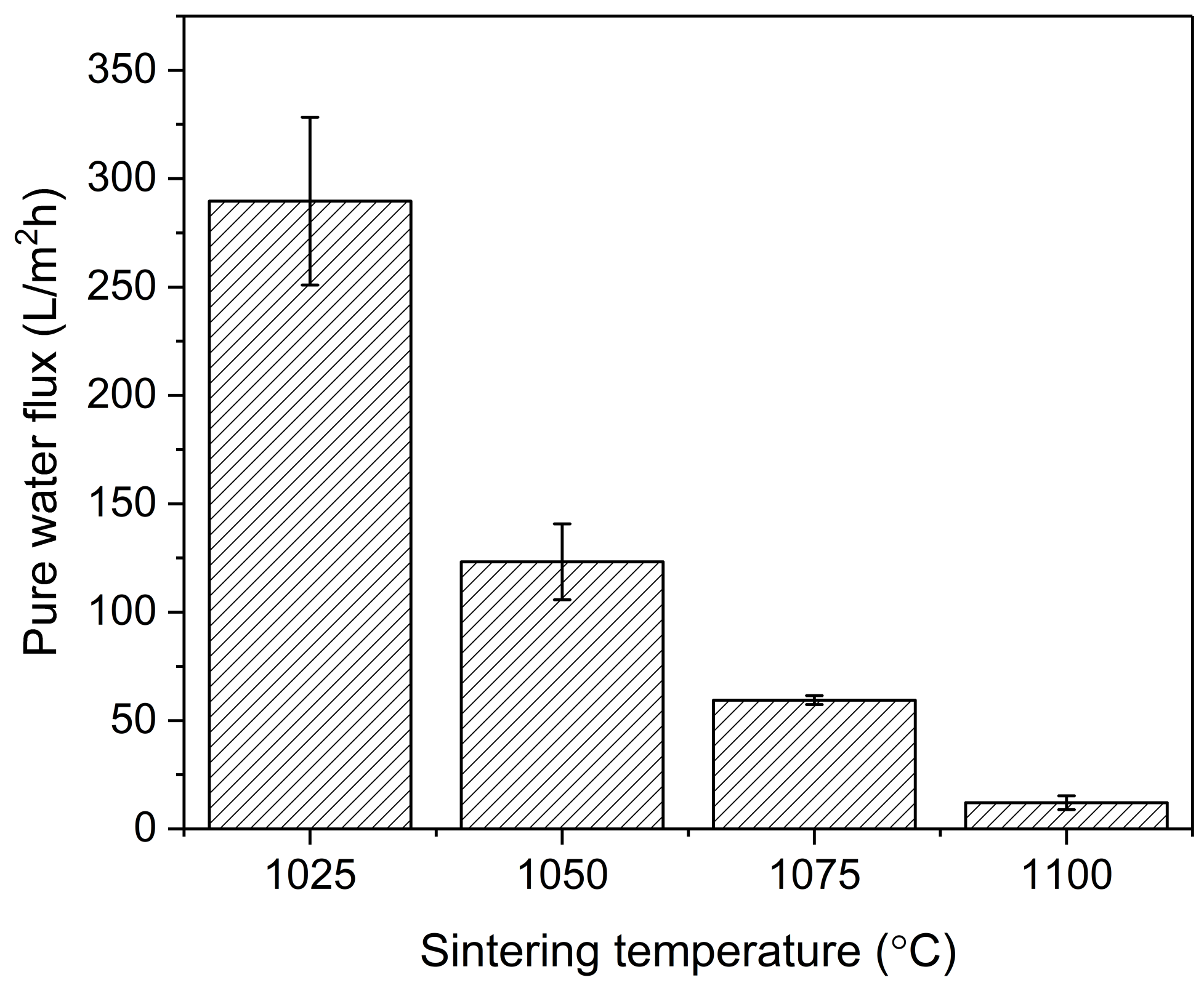

Figure 10

PWF of the CHFM sintered at different temperatures (Operating pressure: 2 bar, $n=3$ ) 